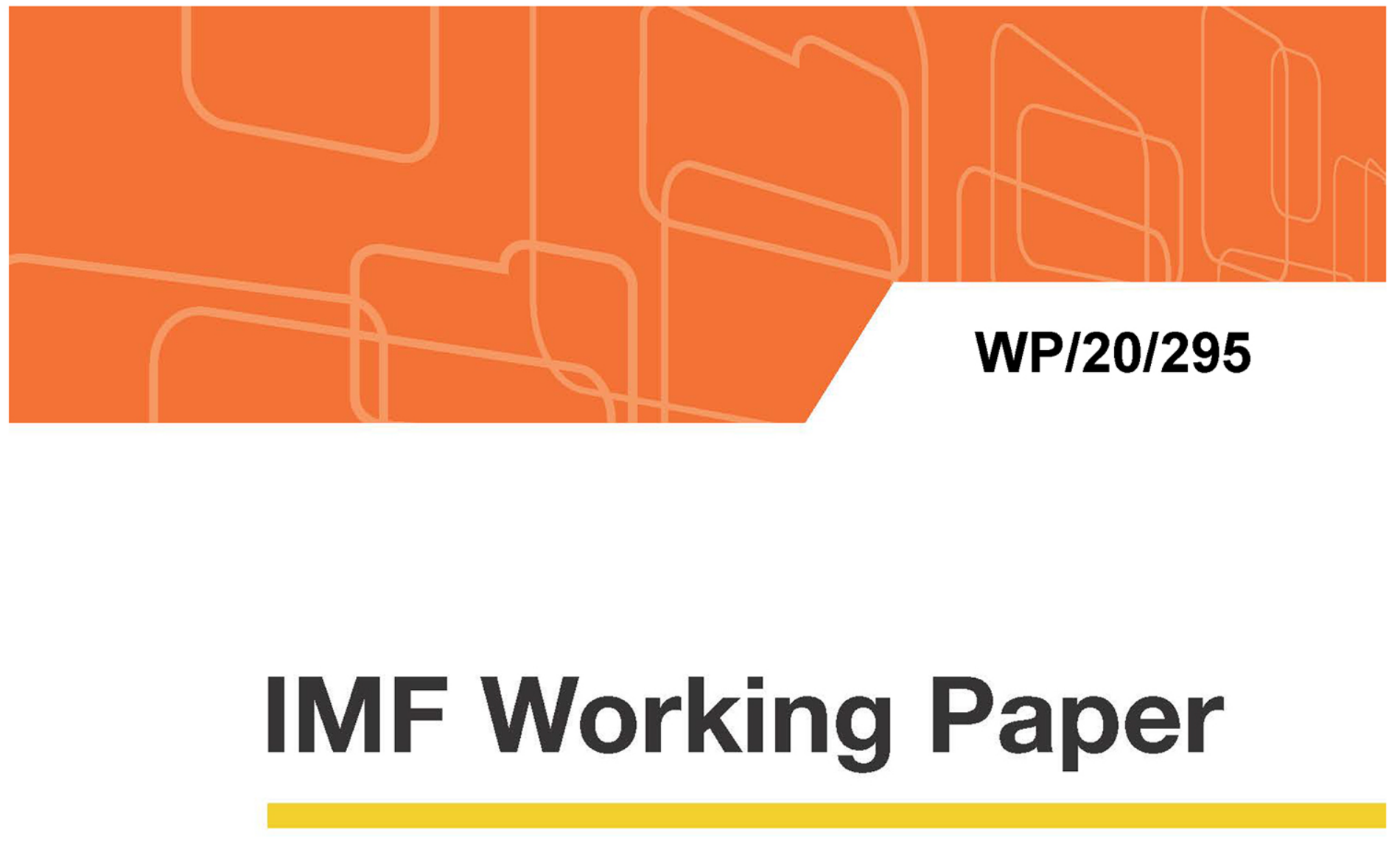

\title{
Quarterly Projection Model for the National Bank of Rwanda
}

\author{
By Jan Vlcek, Mikhail Pranovich, Patrick Hitayezu, Bruno Mwenese, Christian \\ Nyalihama
}

IMF Working Papers describe research in progress by the author(s) and are published to elicit comments and to encourage debate. The views expressed in IMF Working Papers are those of the author(s) and do not necessarily represent the views of the IMF, its Executive Board, or IMF management.

$$
\text { I N T E R N A T I O N A L M O N E T A R Y F U N D }
$$




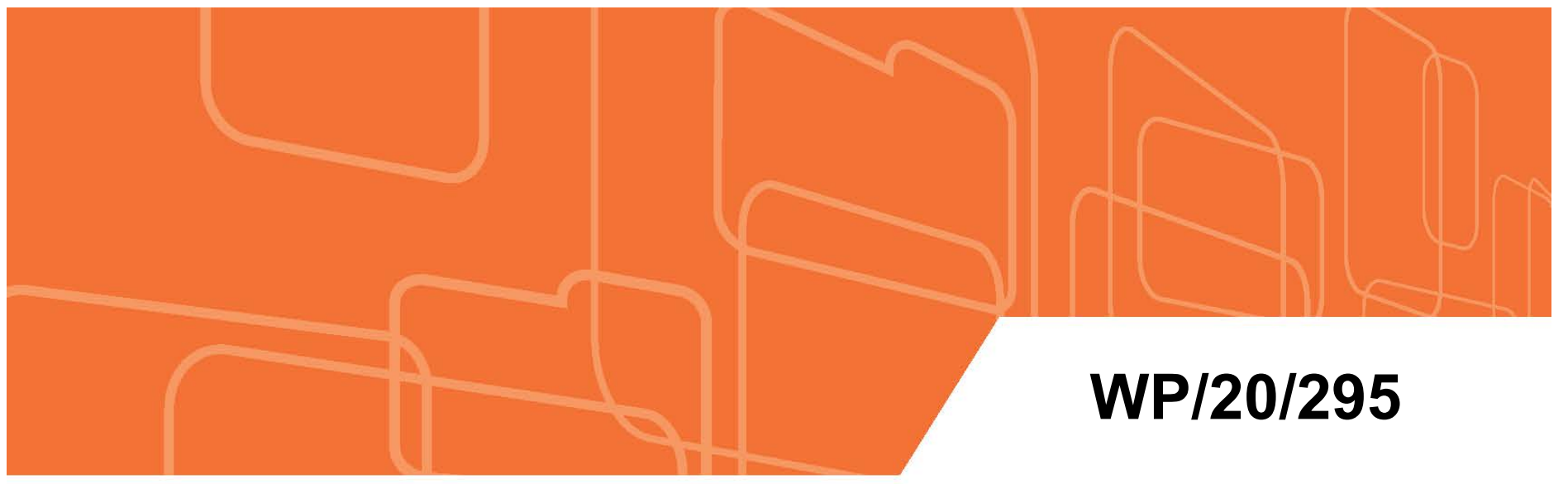

\title{
IMF Working Paper
}

\section{Quarterly Projection Model for the National Bank of Rwanda}

\author{
By Jan Vlcek, Mikhail Pranovich, Patrick Hitayezu, Bruno Mwenese, Christian
}

Nyalihama

IMF Working Papers describe research in progress by the author(s) and are published to elicit comments and to encourage debate. The views expressed in IMF Working Papers are those of the author(s) and do not necessarily represent the views of the IMF, its Executive Board, or IMF management.

I N T E R N A T I O N A L M O N E T A R Y F U N D 
(C) 2020 International Monetary Fund

$\mathrm{WP} / 20 / 295$

\author{
IMF Working Paper \\ Institute for Capacity Development \\ Quarterly Projections Model for the National Bank of Rwanda ${ }^{1}$ \\ Prepared by Jan Vlcek, Mikhail Pranovich, Patrick Hitayezu, Bruno Mwenese, and \\ Christian Nyalihama
}

Authorized for distribution by Valerie Cerra and Paul Cashin

December 2020

IMF Working Papers describe research in progress by the author(s) and are published to elicit comments and to encourage debate. The views expressed in IMF Working Papers are those of the author(s) and do not necessarily represent the views of the IMF, its Executive Board, or IMF management.

\begin{abstract}
National Bank of Rwanda (BNR) modernized monetary policy and transited to the price-based policy framework in January 2019. The Forecasting and Policy Analysis System (FPAS) is the cornerstone for the new forward-looking framework, which mobilizes and organizes resources and sets processes for regular forecasting rounds. The core of this system is a structural macroeconomic model for macroeconomic analysis and projections to support the BNR staff's policy recommendations to the monetary policy committee. This paper documents the quarterly projection model (QPM) at the core of the FPAS at the BNR. The model is an extension of the canonical structure in Berg et al (2006) to reflect specifics of the interest-rate-based policy framework with a managed exchange rate, the effect of agricultural sector and harvests on prices, and the role of fiscal policies and aid flows.

JEL Classification Numbers: E47, E52, C54

Keywords: Rwanda, Forecasting and Policy Analysis, Quarterly Projection Model, Monetary Policy, Managed Exchange Rate, Fiscal Impulse, Aid

Authors’ E-Mails: janvlcekatcz@gmail.com, mpranovich@,imf.org, phitayezu@bnr.rw, bmwenese@bnr.rw, cnyalihama@,bnr.rw
\end{abstract}

\footnotetext{
${ }^{1}$ Technical assistance and customized training missions, which led to the development of this model, were provided within the project on Building a Forecasting and Policy Analysis System at the National Bank of Rwanda. This project has been led by ICD in 2016-2020 and financed by the East AFRITAC. This working paper is part of the research project in low-income countries financed by the Department of International Development (DFID), UK. Authors gratefully acknowledge comments provided on the draft of this paper by Andy Berg and Diego Rodriguez Guzman (both ICD), Thomas Harjes (MCM) and Martha Woldemichael (AFR).
} 


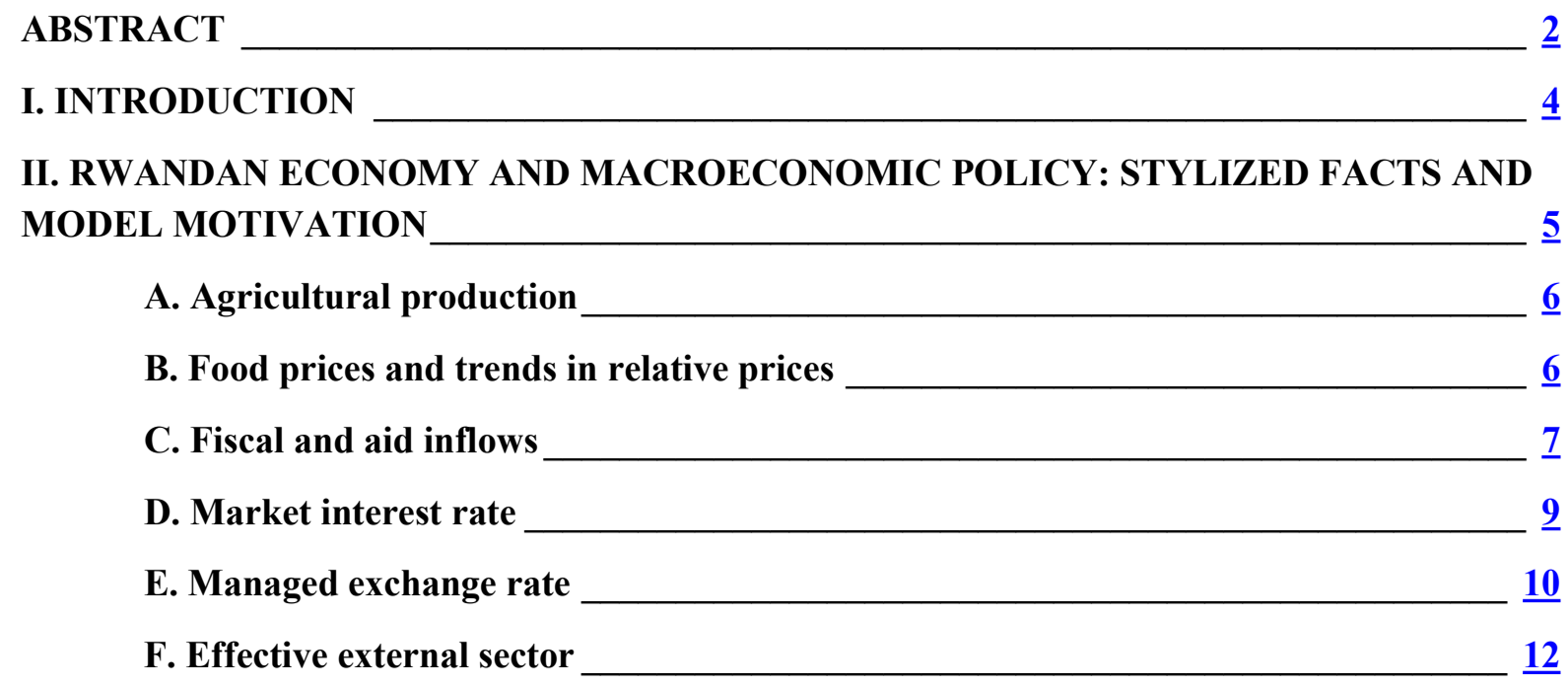

III. STRUCTURE AND FEATURES OF THE QPM FOR THE NATIONAL BANK OF RWANDA _ 13

A. Agricultural and non-agricultural output

B. Inflation block _ $\underline{15}$

C. Monetary policy and exchange rate framework __ 18

D. Fiscal block _ $\underline{20}$

E. Aid — 21

F. External sector

G. Money demand ___ $\underline{22}$

IV. MODEL CALIBRATION AND PROPERTIES___ $\underline{23}$

V. MODEL SIMULATIONS AND HISTORICAL DATA INTERPRETATION___ $\underline{29}$

VI. CONCLUSION AND THE WAY AHEAD ___ $\underline{37}$ 


\section{INTRODUCTION}

The National Bank of Rwanda (BNR) moved away from monetary targeting (thereby modernizing monetary policy) and adopted the price-based policy framework in January $2019 .{ }^{2}$ This shift was taking place as the conditions necessary for the satisfactory functioning of the previous money targeting strategy - in particular, the stability of the money demand function were no longer reliable. Additionally an important factor has been the regional integration in East African Community (EAC) and aspirations to establish East African Monetary Union (EAMU) with a single currency ${ }^{3}$. Transition to the price-base monetary policy framework, developing interbank markets and monetary policy instruments according to common principles are the agreed steps towards harmonization of monetary policy in member countries.

Such a process requires rethinking virtually all elements that define a modern central bank conducting forward-looking monetary policy: the analytical framework to underly policy decisions, the process of communicating staff analyses and macroeconomic projections to the governing body, the decision-making process, the framework for policy implementation, and operations and external policy communications. ${ }^{4}$

With the assistance from the IMF, the BNR seeks to develop a Forecasting and Policy Analysis System (FPAS), which provides an analytical framework in the new policy setup and informs policy making. Establishing a FPAS is usually a multi-year project, which aims at developing staff capacity to conduct macroeconomic analysis, establishing the staff forecasting team (FT) that is responsible for policy analysis and projections, organizing the process to prepare macroeconomic projections, streamlining internal communications between the FT and policymakers, and developing the means for effective external policy communications.

A structural macroeconomic model is usually the central element, the core, of FPAS. ${ }^{5}$ Such a model is meant to reflect a consensual view of the central bank on the workings of the policy transmission mechanism and reflects key features of the domestic economy. However, sustaining the model development and application for policy analysis requires establishing all other elements, organization and processes of FPAS, including centralized database, satellite sectoral models, interdivisional forecasting team, forecasting calendar, internal meetings, and communications.

\footnotetext{
${ }^{2}$ See Rwangombwa (2018).

${ }^{3}$ Burundi, Kenya, Rwanda, Tanzania and Uganda participate in EAC. See also Rusuhuzwa and Masson (2012) and UN (2018) for discussion of the EAC.

${ }^{4}$ See IMF (2015).

${ }^{5}$ See CNB (2003) and Karangwa (2018).
} 
The paper presents a structural quarterly projection model (QPM) of the National Bank of Rwanda developed within the IMF technical assistance project on FPAS up to the end of 2019. We discuss (i) the model structure, (ii) the features to match the stylized facts of the Rwandan economy and particularities of the monetary policy framework, and (iii) calibration of the model and its properties. The canonical model of this type for a central bank pursuing an inflation targeting strategy and steering the interest rate to achieve inflation objective has been introduced in Berg et al. (2006a). Hence, when outlining the QPM in this paper, we use the canonical model as a reference to highlight the elements of it that are key characteristics for Rwanda.

The model proposed here differs in several ways from the one proposed in the earlier work by Charry et al. (2014). First, while a more common approach and the one in Charry et al (2014) is to model the total GDP output gap, in our model we decompose it to agricultural and nonagricultural production, which acknowledges different determinants for agricultural and nonagricultural output and their different implications of sectoral activity for inflation dynamics. Second, the fiscal policy and aid flows are explicitly present, helping to determine fiscal stimulus as a proxy for fiscal policy effects on the real economic activity. Third, we acknowledge the imperfections in money market operations of the central bank and extend the policy block to reflect implications for policy transmission. Finally, the model introduces trends in relative prices which were not considered in Charry et al. (2014). These differences provide for richer model and are important for interpretation of actual data dynamics as well as for forecasting of future economic developments.

The rest of the paper comprehensively documents the QPM for Rwanda. We discuss key stylized facts and motivation of model blocks in section II, and present the structure and key model features in section III. In section IV we highlight model properties and calibration checks. We discuss some steps going forward to develop the QPM and the policy framework more broadly in section V.

\section{Rwandan Economy and Macroeconomic Policy: Stylized Facts and Model Motivation}

To ensure its relevance for monetary policy making the model incorporates several key stylized facts of Rwandan economy and the BNR policy framework. In particular, specific model elements that make it different to that in Berg (2006a,b) are related to (i) a substantial share of agricultural production in total output, (ii) a high share of food items in total consumption basket, (iii) a significant role of fiscal policy and aid inflows, (iv) peculiarities in the short-term money market and BNR's liquidity management, (v) the exchange rate regime, and (vi) trade links. 


\section{A. Agricultural production}

The share of agriculture production on GDP is high at more than 25 percent of total output, Figure II.1. In 2007, the share was close to 32 percent and it has been declining since then by about 0.5 percentage points per annum. Still, the share remains high, which is often the case in low-income economies in Africa.

Agricultural production is driven by factors different from the usual ones affecting the business cycle. Weather conditions have substantial impact on harvests, while factors like real monetary conditions, fiscal expenditure and foreign demand have rather limited influence on agricultural production. In what follows, we take this into account and model agricultural and non-agricultural production separately. Volatility of weather conditions and harvests also contribute to larger volatility of total GDP, Figure II.2.

\section{Figure II.1: Share of agricultural production on total GDP, percent}

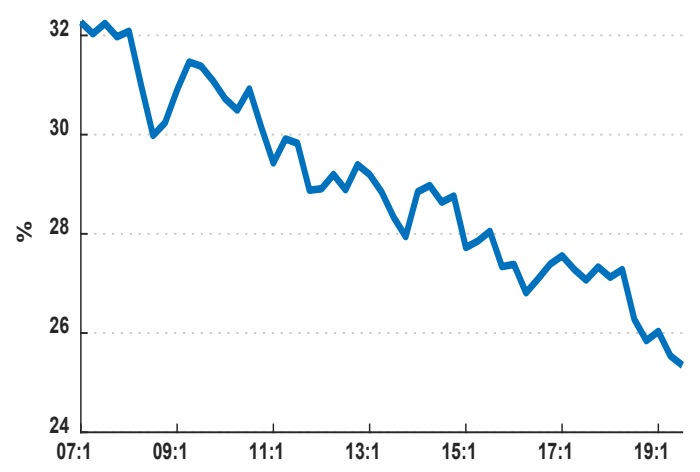

Source: Authors' computations and BNR
Figure II.2: Contributions to real y-o-y GDP growth, p.p.

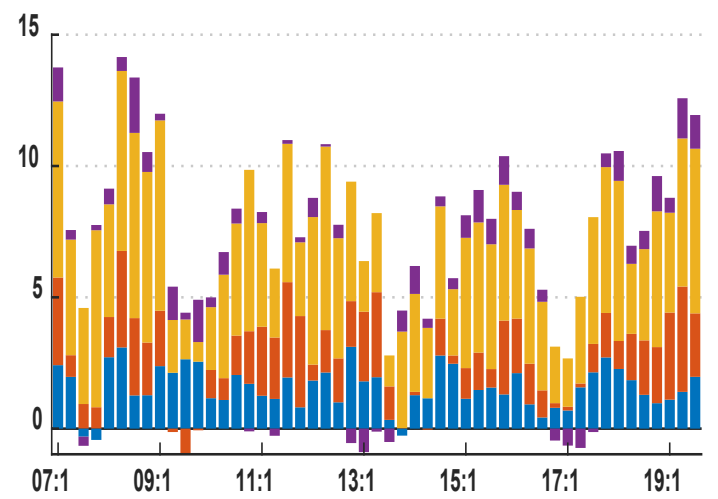

\begin{tabular}{l|l|l|l|l|l|l} 
Angriculture & Industry & Service & Taxes
\end{tabular}

Source: Authors' computations and BNR

\section{B. Food prices and trends in relative prices}

The share of food and beverages articles in the Rwandan total consumption basket is relatively large at 32 percent. ${ }^{6}$ The remaining parts of CPI include core and energy items accounting for 61 and 7 percent respectively.

Food prices are volatile and partly are driven by factors beyond the business cycle. Given that Rwanda is a small open economy, which imports and exports food, the food prices in Rwanda are impacted by

\footnotetext{
${ }^{6}$ The food items are in COICOP1 and COICOP2 groups of the CPI basket. Hence the QPM definition of food subcomponent differs from the one disseminated by the National Institute of Statistics, which is based only on COICOP1 group.
} 
the world food prices and the Rwandan franc (FRW) exchange rate developments. In 2018, foodstuff, vegetable products, and animals accounted for about 15 percent of total imports with highest shares attributed to raw sugar and wheat. About 15 percent of total exports was domestically produced coffee and tea. Importantly, the food prices are also sensitive to harvests in the domestic agricultural sector, which are difficult to predict as they are affected by rainfalls and weather conditions more generally. Hence, the marginal costs of producing food in Rwanda should account for world food prices, exchange rate dynamics, and local harvests. Given their high share and volatility, food prices have been contributing to the volatility of the headline inflation, Figures II.3 and II.4.

Figure II.3: Decomposition of the headline inflation (y-o-y) to subcomponents, percentage points

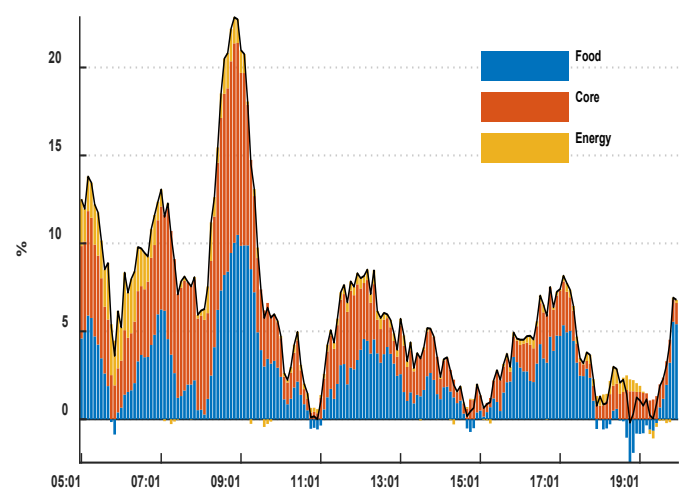

Source: Authors' computations and BNR

Figure II.5: Price indices, 2005M1=100, percent

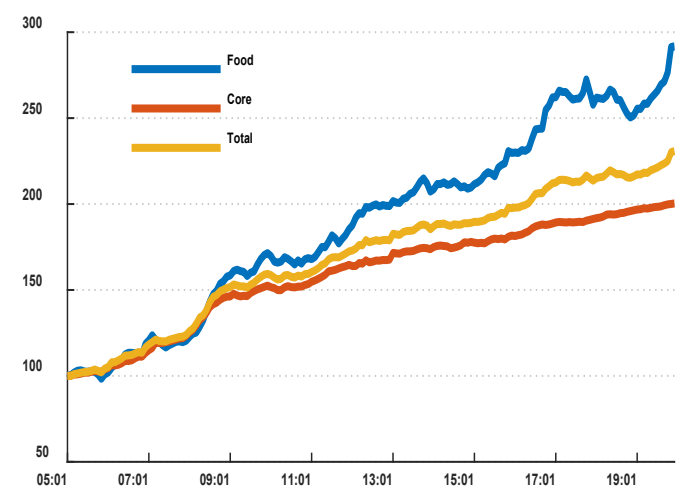

Figure II.4: Food price inflation, y-o-y, percent

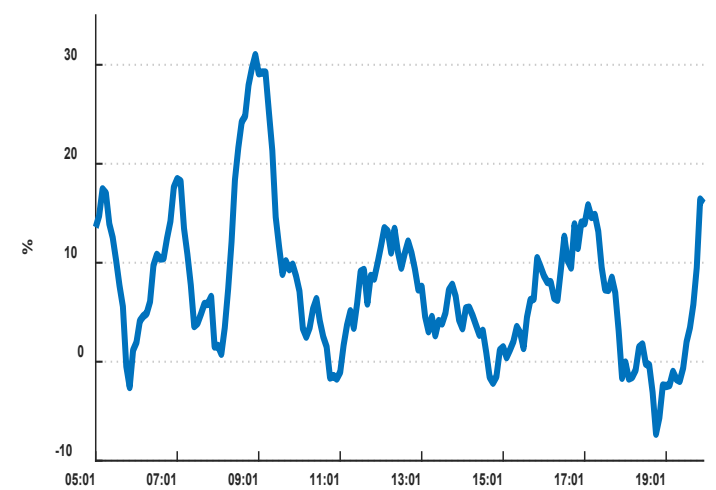

Source: Authors' computations and BNR

Average food price inflation in Rwanda exceeded headline and core inflation over the historical period, Figure II.5. Such dynamics conditioned non-stationary relative prices, which is accounted for in the QPM via modelling trends in core, food and energy CPI subcomponents relative to the headline CPI.

Source: Authors' computations and BNR

\section{Fiscal and aid inflows}

Public expenditures, namely central government expenditures, play an important role shaping real economic activity in Rwanda. Expenditures channeled via the budget include those financed by substantial international aid and concessional borrowing. 
Rwanda belongs to a group of countries receiving large aid inflows. Prior to 2010, such flows were reaching about 15 percent of GDP on average per annum and peaking at more than 20 percent in 2004, Figure II.6. Although the share has declined to about 12 percent in 2018 since then, the aid inflows remain significant source of funds for the government.

Total government expenditures - including those financed by aid inflows and borrowing from abroad - relative to GDP have increased to about 30 percent in 2019 from about 20 percent in 2000, Figure II.7. The fast increase of expenditures relative to GDP in last couple of years, in particular, has been driven by financing large infrastructure projects.

Figure II.6: Share of net official aid inflows on total GDP, percent

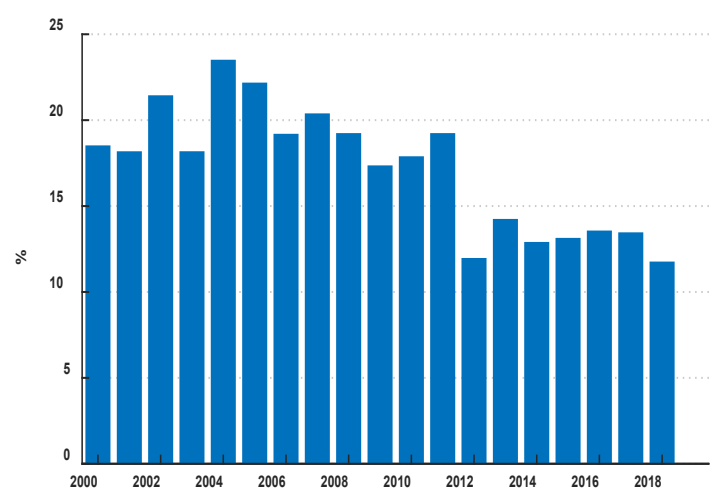

Source: World development indicator database
Figure II.7: Share of total government expenditures on GDP (including net borrowing), percent

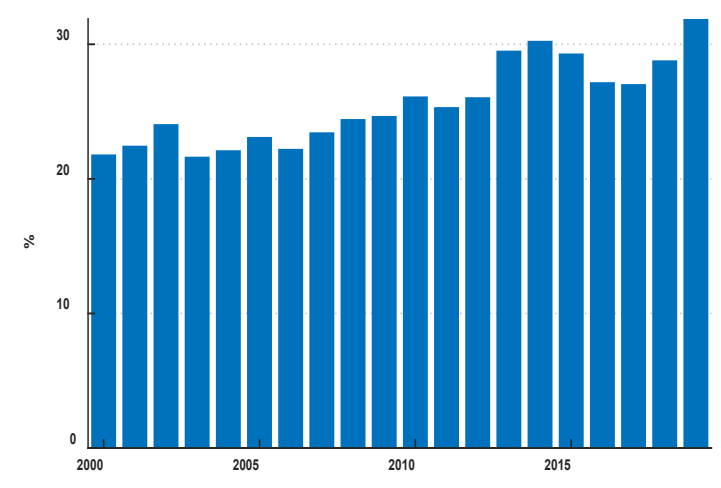

Source: World development indicator database

The share of government spending in GDP is similar to advanced countries nowadays as it was growing in the past. The share of government consumption increased to above 15 percent recently, Figure II.8, contributing significantly to dynamics and variability of real GDP, Figure II.9.

Figure II.8: Share of government consumption on total GDP, percent

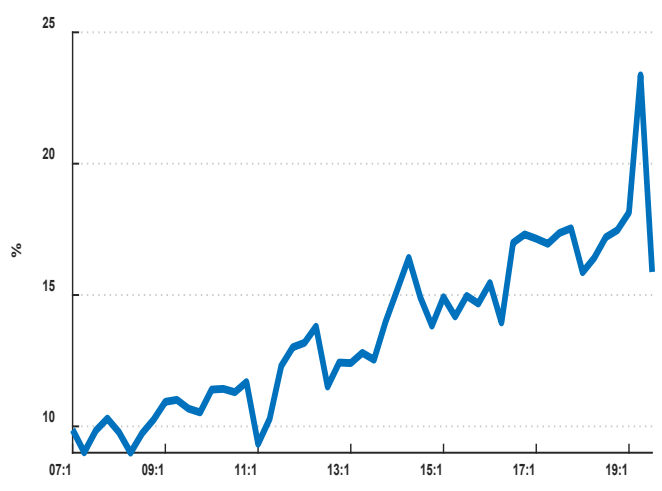

Source: Authors' computations and BNR
Figure II.9: Contributions to y-0-y real GDP growth, p.p.

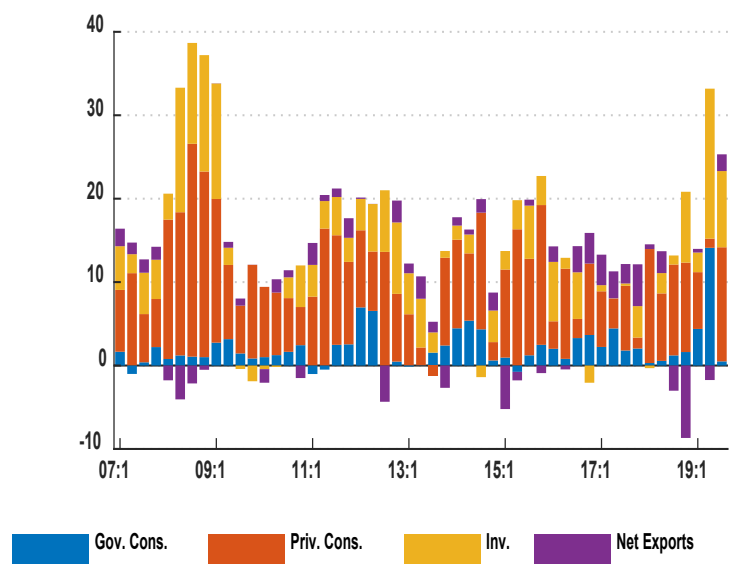

Source: Authors' computations and BNR 
We consider effects of public expenditures and aid on macroeconomic developments through several measures in the QPM. The fiscal impulse in the model is the change in the cyclicallyadjusted deficit plus the change in exceptional expenditures, and does not include changes in aidfinanced expenditure. This measure captures the discretionary element of fiscal policy, which is net of the effect of fiscal automatic stabilizers. We separate the aid-financed expenditures because inflow of international aid is not under the direct discretion of the domestic government and is assumed to be exogenous to the domestic business cycle. However, such expenditures still impact the aggregate demand and therefore we define another impulse-like variable in the model to capture their effect on output in the short-run.

\section{Market interest rate}

The BNR is transitioning to the policy framework based on using the interest rates as the operational target. ${ }^{7}$ The move away from monetary aggregate targeting has been announced in the beginning of 2019. However, the de-facto transition to this framework started earlier in 2008 when the Key Repo Rate (KRR) has been introduced as a key policy rate. Subsequently, the interest rate corridor was introduced in 2012 with the discount rate and the deposit rate respectively upper and lower bounds of the corridor, Figure II.10.

In the past, the overnight interbank money market rate was not fully aligned with the announced policy interest rate. The banking system in Rwanda has a number of structural challenges and swings in liquidity conditions in the money market has been significant over the history and not neutralized by the central bank open market operations (OMOs). In addition to that, the marginal interest rate set by the BNR for its own REPO operations - the main OMOs - has itself been deviating significantly from the announced KRR limiting the policy signaling effect of the latter rate. All such factors, led to persistent deviations of the overnight interbank money market rate from KRR, which were particularly notable during 2010-2016.

Since 2016, the BNR lifted the marginal REPO rate, which allowed to reduce the margin between that rate and the announced KRR. Also, the BNR has been more active mopping up excess liquidity. As a result, the overnight interbank money market became more active both in terms of the number of transitions and turnover. The interbank became more aligned with the KRR in 2017 2018, Figure II.11. In the second half of 2019, the liquidity position of the system changed drastically from excess to shortage of liquidity and the BNR switched from mopping up liquidity via REPO to injecting via reverse REPO. However, once again the marginal rate in OMOs have

\footnotetext{
${ }^{7}$ See Rwangombwa (2018).
} 
not been aligned and exceeded the announced KRR, leading to the upward deviations of the interbank market rate from the KRR.

Figure II.10: KRR, interest rate corridor and
overnight interbank interest rate, percent p.a.

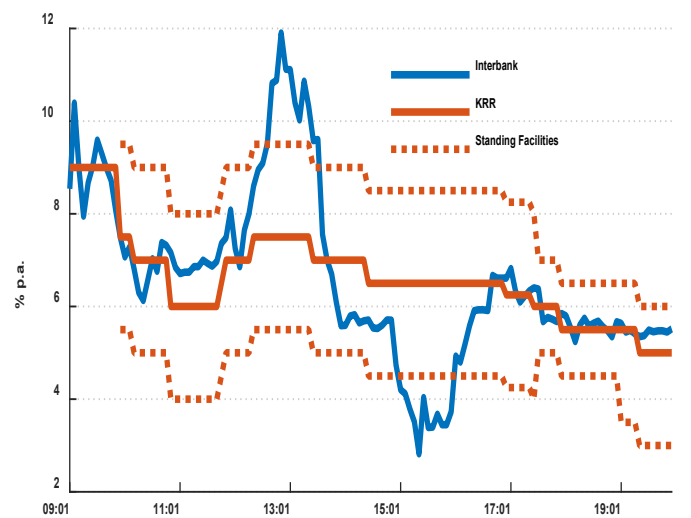

Source: BNR
Figure II.11: KRR, REPO and overnight interbank interest rate, percent p.a.

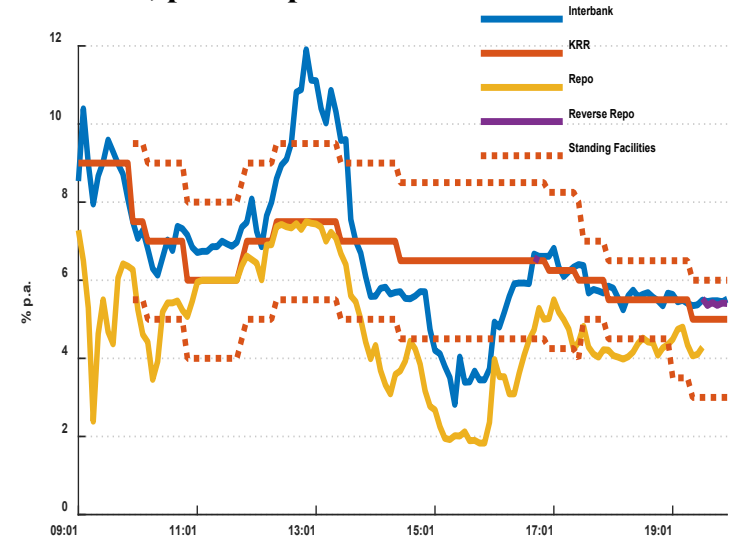

Source: BNR

Imperfections in the market and in liquidity management and resulting developments in terms of interest rates need to be carefully accounted for in the QPM. Given limited variability of the announced KRR and its disconnect from the interest rate the BNR used in OMOs - the REPO rate - we do not directly incorporate the KRR in the QPM. Instead, in the model we treat the REPO rate (and the reverse REPO in the second half of 2019) as the key policy rate that the BNR steers to impact macroeconomic conditions. ${ }^{8}$ The overnight money market rate in the model affects aggregate monetary conditions and it is linked to the policy rate via the premium, which captures persistent deviations of the overnight rate from the policy rate. ${ }^{9}$

\section{E. Managed exchange rate}

Capital controls along with imperfect substitutability of domestic and foreign assets allow the BNR to manage the exchange rate together and to steer the interest rate at the same time. Although Rwanda removed some capital controls, the Chinn-Ito index (Figure II.12) indicates

\footnotetext{
${ }^{8}$ This can also be seen as acknowledging that what the central bank actually does by defining the cost of liquidity in its OMOs is more important than what it says it does, when announcing the KRR.

${ }^{9}$ This is in contrast to the more orthodox way of incorporating the short-term money market in the QPM and treating it as fully aligned with the policy rate, which is a reasonable approach when liquidity management ensures that there are no deviations of the market rate from the key policy rate.
} 
Capital controls along with imperfect substitutability of domestic and foreign assets allow the BNR to manage the exchange rate together and to steer the interest rate at the same time. Although Rwanda removed some capital controls, the Chinn-Ito index (Figure II.12) indicates that some capital controls are still in place, their extent however significantly diminished during 2010-2014.

Figure II.12: Chinn-Ito index of capital controls $(0=$ full control, $1=$ no constraints)

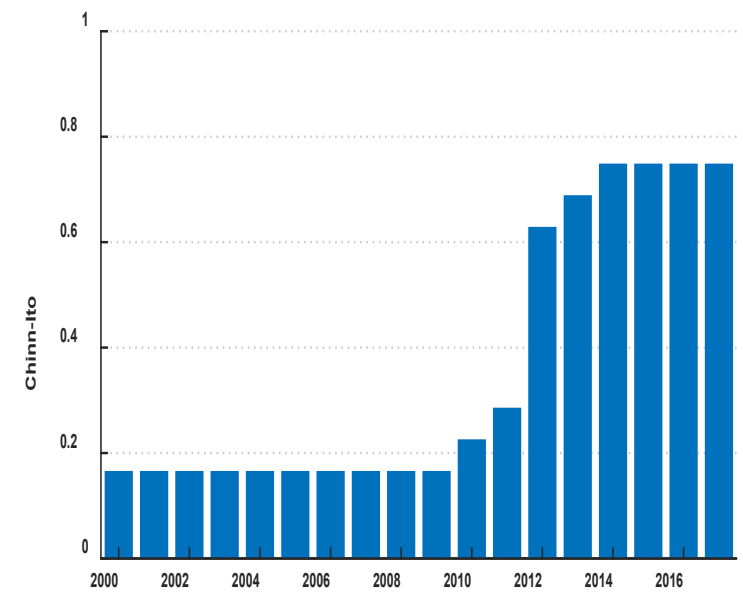

Source: http://web.pdx.edu/ ito/Chinn-Ito_website.htm
The BNR has been managing the exchange rate of FRW vis-à-vis USD and transacted in the FX market, which substantially limited volatility of the exchange rate, Figure II.13 and II.14. According to the AREAER 2018 the de facto exchange rate regime is classified as a crawl-like arrangement and the BNR discloses data on its FX interventions. We note also that the depreciation rate (the rate of crawl) changes over time, which indicates that the BNR uses it as an additional operating target and corrects the rate in response to domestic currency misalignment and inflation. The

latter is reflected in the QPM via introducing the rule-like equation for the targeted rate of nominal depreciation.

Figure II.13: Nominal exchange rate, FRW per 1 USD

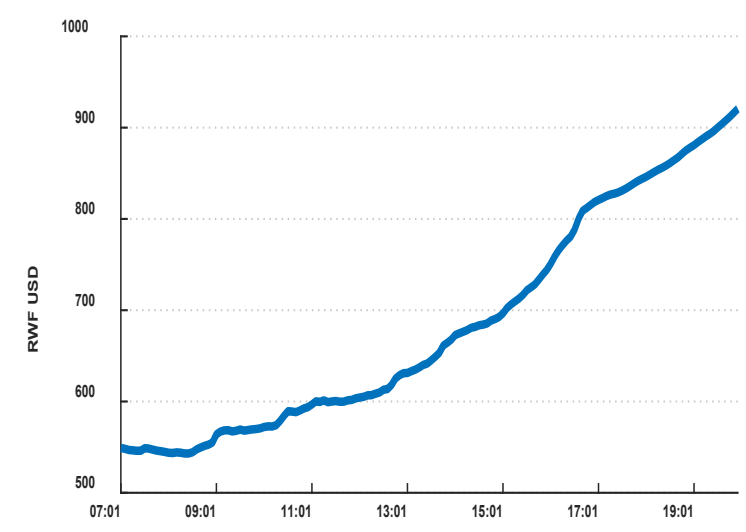

Source: Authors' computations and BNR
Figure II.14: Nominal exchange rate depreciation, y-o-y, percent

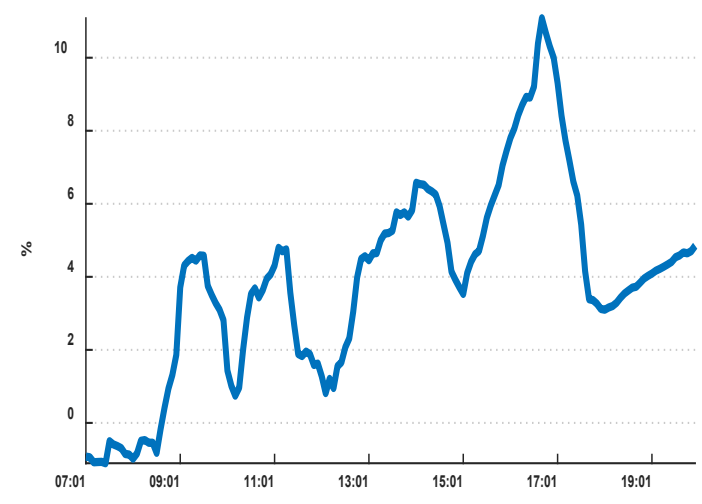

Source: Authors' computations and BNR 
Figure II.15: Real exchange rate vis-a-vis USD, 100*In

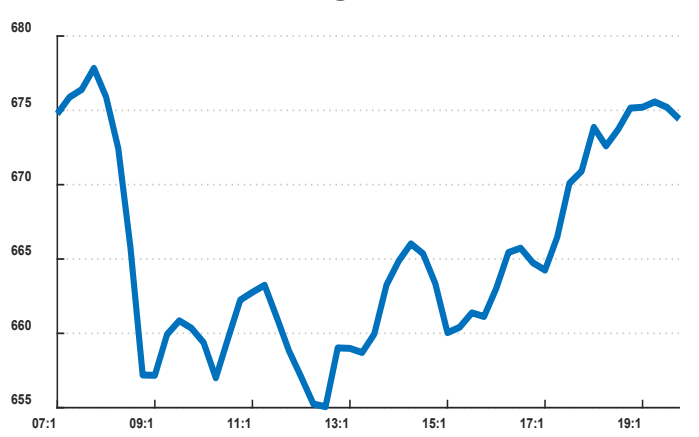

Source: Authors' computations and BNR
Both, the nominal and the real exchange rate vis-a-vis USD have been depreciating over the analyzed historical period. Nominal exchange rate depreciation reflects a positive inflation differential with respect to the US along with some depreciation in real terms. While Rwanda experienced relatively stable real exchange rate during 2009-2015, real depreciation took place afterwards (Figure II.15) and FRW lost about 10 percent of its

value to USD during 2015-2019. Notably, despite the high rates of economic growth, we do not observe appreciation of FRW in real terms, which, for example, where quite characteristic for emerging economies in Eastern and Central Europe. ${ }^{10}$ This could be a result of violation of conditions that underly Harrod-Balassa-Samuelson effect: the exports from Rwanda are to a large extent food products, in particular coffee and tea, and productivity gains in this sector may be insufficient to inspire pressures on the labor market and wages in the non-tradable sector. The growth and productivity gains maybe primarily in the non-tradable sector. ${ }^{11}$

\section{F. Effective external sector}

Rwanda is a small open economy and many of its trading partners are developing economies from SubSaharan Africa. Rwandan total export is about 20 percent of GDP and primarily consist of common agricultural products, including coffee and tea. The ratio of imports to GDP is about 40 percent and it includes fuels and food items mainly. The share Sub-Saharan countries in Rwandan trade flows account for about 25 percent of imports and 45 percent of exports, see Figures II.16 and II.17.

Figure II.16: Import share of countries, \% in 2018

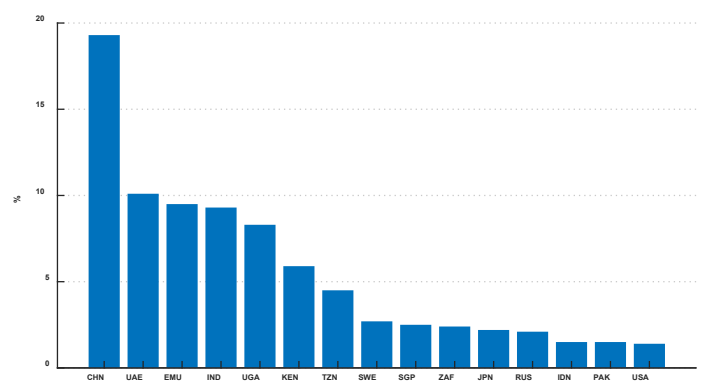

Figure II.17: Export share of countries, \% in 2018

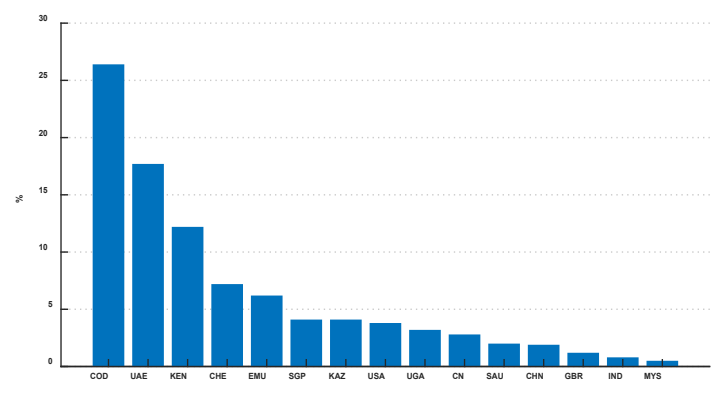

Source: Authors' computations and IMF's direction of trade database

\footnotetext{
${ }^{10}$ See Egert and Podpiera (2008).

${ }^{11}$ See, for example, Bergin, P., Glick, R. and A. M. Taylor (2006) discussing how the presence of the HarrodBalassa-Samuelson effect may depend on relative TFP advances in tradable vs. non-tradable sectors.
} 
Aggregate demand and inflation in Rwanda are exposed to economic developments in trading partners via the trade channel. In the ideal world, the QPM for Rwanda would include external sector with model blocks for a large of key trading partners, including Sub-Saharan economies.

At the current juncture, having such a broad external sector in the QPM appears impractical. The more countries are included in the model, the more complicated the model becomes and the higher is the demand for historical data for such countries. Moreover, when developing macroeconomic projections, the BNR staff would need to either produce their own macroeconomic forecast for all trading partners in the QPM with the large external block or have stable access to such forecasts produced by third parties. None of these solutions seems to be immediately available currently. To produce own macroeconomic forecast for trading partners, the BNR staff would need to develop a set of macroeconomic models for such countries, which is not impossible but would be a large investment of resources for a relatively small central bank. Availability of regular, i.e. quarterly, and timely, i.e. during the forecasting cycle prior to the new monetary policy committee (MPC) meeting, macroeconomic forecasts from third parties for smaller economies among Rwandan trading partners appears to be limited as well.

The effective foreign sector nevertheless has to be present in the QPM for a small open economy of Rwanda. The model includes macroeconomic variables for Eurozone and the US to approximate global macro-developments. This also implies that such macro-developments are seen as a common factor which drives developments in trading partners of Rwanda and hence affect domestic macroeconomic dynamics, even if indirectly. The approach with approximating the effective external sector with a small set of large economies also addresses historical data availability and timely and regular availability of macroeconomic projections for such economies. ${ }^{12}$ It also helps to preserve simpler model structure and, in particular, avoid modelling effective exchange rate and have only one bilateral exchange rate vis-à-vis USD in the model the one which is also managed in the de-facto crawling peg arrangement.

\section{STRuCture ANd Features OF THE QPM FOR THE NATIONAL BANK OF RWANDA}

This part describes how Rwandan stylized facts are reflected in the structure and parameterization of the QPM. We highlight equations in the Rwanda QPM that are different from the canonical workhorse model in Berg et al. (2006a) and Berg et al. (2006b). All variables are in natural logs unless stated otherwise. The full set of model equations is listed in Appendix A.

\footnotetext{
${ }^{12}$ In particular, the BNR staff uses Fed and ECB macroeconomic projections for US and EMU respectively and the IMF projections for global commodity prices of oil and food.
} 


\section{A. Agricultural and non-agricultural output}

The real output in the model is split into agricultural and non-agricultural production. Both agricultural and non-agricultural outputs are decomposed into gap and trend unobserved components. The rate of output growth or gap are then determined as a linear combination of sectoral rates or gaps respectively:

$$
\begin{aligned}
& \Delta y_{t}=w^{a g r} \Delta y_{t}^{a g r}+\left(1-w^{a g r}\right) \Delta y_{t}^{n a g r}, \\
& \hat{y}_{t}=w^{a g r} \hat{y}_{t}^{a g r}+\left(1-w^{a g r}\right) \hat{y}_{t}^{\text {nagr }},
\end{aligned}
$$

where $\Delta y$ and $\hat{y}$ is a quarter-on-quarter (q-o-q) real GDP rate of growth and gap respectively, $\Delta y^{a g r}$ and $\hat{y}^{a g r}$ are for agricultural GDP, and $\Delta y^{\text {nagr }}$ and $\hat{y}^{\text {nagr }}$ are for non-agricultural GDP. The weight $w^{a g r}$ is the share of agricultural product on total GDP.

Agricultural output gap in the Rwanda QPM is assumed to follow a simple AR process. Agricultural sector in Rwanda very much depends on harvests and weather conditions, and the usual demand side business cycle factors, including monetary and fiscal stance, do not appear to explain much of its variation. On top of that, comprehensive data on rainfalls and weather conditions - the supply side factors, which should have explanatory power for agricultural production - were missing at the time of developing the model. Hence, the model choice is constrained to a "technical" description as an AR-process:

$$
\hat{y}_{t}^{a g r}=b_{11} \hat{y}_{t-1}^{a g r}+\varepsilon_{t}^{\hat{y}^{a g r}}
$$

where $\epsilon^{\hat{y}^{a g r}}$ is the shock to the agriculture output gap.

Such specification leaves challenges for using the model for macroeconomic projections. In particular, when producing the forecast, the BNR staff should treat agricultural production as an exogenous process and hence to use external information (surveys of agricultural producers) to assess supply effects in this sector and make judgement about near-term and medium-term developments in agricultural output. A non-zero agricultural gap usually reflects good or bad harvest, with a subsequent effect on food prices, modelling of which is discussed in the following subsections.

The non-agricultural output gap in the short-run is driven by the demand side factors. In addition to the foreign output gap and monetary conditions as in the canonical model, the non-agricultural output gap in the QPM for Rwanda is affected by fiscal and aid flows. The fiscal policy impacts output via the fiscal impulse which is a change in the ratio of cyclically-adjusted deficit to GDP. Changes in the gap of the ratio of aid to GDP are included in the equation for the non-agricultural 
gap as another demand driver. Fiscal impulse and aid are also discussed in more details in the next subsections.

$$
\hat{y}_{t}^{\text {nagr }}=b_{12} \hat{y}_{t-1}^{\text {nagr }}-b_{22} r m c i_{t}+b_{32} \hat{y}_{t}^{*}+b_{42} f i m p_{t}+b_{52}\left(\widehat{a} \widehat{2}_{t}-\widehat{a} \widehat{y}_{t-1}\right)+\varepsilon_{t}^{\hat{y}^{n a g r}},
$$

where fimp is a fiscal impulse and $\widehat{a} \widehat{2 y}$ is the gap for the ratio of aid to GDP. The real monetary condition index rmci is defined similarly to the one in the canonical model as the weighted average of the real interest and the real exchange rates.

\section{B. Inflation block}

Inflation of consumer prices is decomposed into three subcomponents: core, food, and energy price inflation. This breakdown allows linking each inflation subcomponent to determinants of real marginal costs that are defined to capture more relevant cost pressures. ${ }^{13}$

The headline CPI is then a weighted average of core, food, and energy CPIs.

$$
c p i_{t}=w^{C} c p i_{t}^{C}+w^{F} c p i_{t}^{F}+\left(1-w^{C}-w^{F}\right) c p i_{t}^{E}+\varepsilon_{t}^{c p i},
$$

where $c p i$ is headline CPI, $c p i^{C}$ is core CPI, $c p i^{F}$ is food component of CPI, and $c p i^{E}$ is for energy component of CPI. The term, $\varepsilon^{c p i}$, is a measurement error introduced to capture discrepancies that appear due to (i) actual sub-components do not sum up to headline CPI ${ }^{14}$ and (ii) weights are constant in the model, while they may be changing over the estimation sample.

\section{Core inflation}

The structure of this equation is similar to that for the headline inflation in the canonical model as in Berg (2006a, b) but it is written for the core q-o-q inflation subcomponent. It incorporates mechanism for formation of inflation expectations and the pass-through of production costs to prices:

$$
\pi_{t}^{C}=a_{11} E_{t} \pi_{t+1}^{C}+\left(1-a_{11}\right) \pi_{t-1}^{C}+a_{21} r m c_{t}^{C}+\varepsilon_{t}^{\pi^{C}},
$$

where $\pi^{C}$ is core q-o-q annualized inflation, $r m c^{C}$ is the real marginal costs of production of core goods, and $\varepsilon^{\pi^{C}}$ is a cost-push shock (supply shock). Agents' inflation expectations is a weighted average of past inflation, $\pi_{t-1}^{C}$, and of inflation expected in the current quarter for the next quarter, $E_{t} \pi_{t+1}^{C}$. Real marginal costs for core inflation are defined as follows:

$$
r m c_{t}^{C}=a_{31} \hat{y}_{t}^{\text {nagr }}+\left(1-a_{31}\right)\left(\hat{z}_{t}-\widehat{r p}_{t}^{C}\right)
$$

\footnotetext{
${ }^{13}$ See Andrle et al (2013b) for a breakdown of headline to food and non-food price inflation in a QPM model.

${ }^{14}$ This is given by changes of in CPI composition and weights of items over the history. The discrepancy is present in the actual data as published by the Statistic Office.
} 
where $\hat{y}^{\text {nagr }}$ is the non-agricultural output gap, $\hat{z}$ is the real effective exchange rate gap, and $\widehat{r p}^{C}$ is the gap in relative prices of core goods and services (core CPI) to prices of the whole consumer basket (headline CPI). Relative prices in the model are defined as the difference of their logs of core and headline CPI:

$$
r p_{t}^{C}=p_{t}^{c}-p_{t}
$$

Then the gap, $\widehat{r p}$, is:

$$
\widehat{r p}_{t}^{C}=r p_{t}^{C}-\overline{r p}_{t}^{C} .
$$

The real marginal costs index in (6) approximates domestic and imported costs producing goods and services in a small open economy of Rwanda. The non-agricultural output gap approximates costs of production related to labor (wages) and capital (rental price of capital). The real exchange rate gap as the price of foreign goods expressed in domestic currency relative to domestic prices captures cost of imported factors of production and ensures that the prices in Rwanda and foreign economies are in line with the relative version of purchasing power parity. When adjusting the real exchange rate gap by the relative price gap, we get the real exchange rate gap defined in terms of the core CPI in Rwanda.

\section{Food price inflation}

Food inflation subcomponent is defined based on the price index for the items including nonalcoholic beverages, nourishing items, alcoholic beverages, and narcotics. ${ }^{15}$ Food inflation is described by the following Phillips curve:

$$
\pi_{t}^{F}=a_{12} E_{t} \pi_{t+1}^{F}+\left(1-a_{12}\right) \pi_{t-1}^{F}+a_{22} r m c_{t}^{F}+\varepsilon_{t}^{\pi^{F}},
$$

where $\pi^{F}$ is food inflation, $r m c^{F}$ are real marginal costs for food prices, and $\varepsilon^{\pi^{F}}$ is a cost push shock (supply shock). Expectation scheme is the same as in the case of core inflation. Real marginal costs for food inflation are defined as the following:

$$
r m c_{t}^{F}=a_{32} \hat{y}_{t}^{\text {nagr }}-a_{42} \hat{y}_{t}^{\text {agr }}+\left(1-a_{32}\right)\left(\widehat{r p}_{t}^{w f o o d}+\hat{z}_{t}-\widehat{r p}_{t}^{F}\right),
$$

where $\hat{y}^{a g r}$ is the agricultural output gap, $\widehat{r p}^{w f o o d}$ is the relative world food prices gap, and $\widehat{r p}^{F}$ is the gap of the relative prices of food to the whole consumption basket. Relative prices and the respective gap for food prices are defined analogously to that for core in (7) and (8). The relative world food price is

$$
r p_{t}^{w f o o d}=p_{t}^{w f o o d}-c p i_{t}^{U S}
$$

with the respective world food price gap:

\footnotetext{
${ }^{15}$ This definition of food CPI corresponds to COICOP01 and COICOP02.
} 


$$
\widehat{r p}_{t}^{w f o o d}=r p_{t}^{w f o o d}-\overline{r p}_{t}^{w f o o d} .
$$

There are notable differences in the composition of real marginal costs (10) in comparison to that for the core inflation in (6). As usual, the non-agricultural output gap proxies the costs of labor and capital which are assumed to increase with the business cycle. The agricultural output gap measures effects of harvests and agricultural production on domestic food prices. In contrast to the non-agricultural gap, it enters (10) with the minus sign. It reflects that the domestic agricultural production above normal (equilibrium) level due to an abundant harvest limits costs of producing food and therefore creates disinflationary pressures. At the same time, Rwanda is an open economy importing and exporting food stuff. The country is a price taker in the global market and thus world food prices matter for prices of imports. The sum of relative world food price gap and the real exchange rate gap ${ }^{16}$ captures costs of imported food stuff and ensures that the price level in Rwanda and foreign economies in the case of food is in line with the relative version of purchasing power parity.

\section{Energy price inflation}

Inflation of energy prices follows Phillips curve:

$$
\pi_{t}^{E}=a_{13} E_{t} \pi_{t+1}^{E}+\left(1-a_{13}\right) \pi_{t-1}^{E}+a_{23} r m c_{t}^{E}+\varepsilon_{t}^{\pi^{E}},
$$

where $\pi^{E}$ is energy price inflation, $r m c^{E}$ are real marginal costs, and $\varepsilon^{\pi^{E}}$ is a cost push shock (supply shock). Again, the mechanism of inflation expectations formation is the same as in the case of core inflation. The real marginal costs variable for energy price inflation is defined as the following:

$$
r m c_{t}^{E}=a_{33} \hat{y}_{t}^{\text {nagr }}+\left(1-a_{33}\right)\left(\widehat{r p}_{t}^{\text {woil }}+\hat{z}_{t}-\widehat{r p}_{t}^{E}\right),
$$

where $\widehat{r p}^{\text {woil }}$ is the real world oil price gap, and $\widehat{r p}^{E}$ is the gap of the relative price of energy CPI to headline CPI. Relative price of energy and headline CPI is defined similarly to that for core in (7) and (8).

The relative world energy price is defined relative to US CPI:

$$
r p_{t}^{o i l}=p_{t}^{\text {woil }}-c p i_{t}^{U S}
$$

with the respective price gap being

$$
\widehat{r p}_{t}^{\text {woil }}=r p_{t}^{\text {woil }}-\overline{r p}_{t}^{\text {woil }}
$$

\footnotetext{
${ }^{16}$ The real exchange rate gap is further adjusted by the relative food price gap to get the real exchange rate gap defined using food CPI, both domestic and foreign.
} 
The non-agricultural output gap in (14) approximates cost pressures on energy prices related to the business cycle. The second term in real marginal costs ensures that Rwanda energy prices follow the world market prices and sum of relative world energy price gap adjusted by the domestic relative price gap and the real exchange rate gap is the price of energy imports in domestic currency relative to energy prices.

\section{Monetary policy and exchange rate framework}

The policy block in the model assumes that monetary policy uses both the policy interest rate and the exchange rate as the short-term operational targets (instruments). The control over the exchange rate is partial. Given some capital controls and less than full substitutability of domestic and foreign assets, the central bank retains the ability to steer domestic interest rates. The QPM framework is flexible and can accommodate various degrees of the control over the exchange rate, ranging from pure float to tightly managed exchange rate.

\section{Exchange rate}

In order to take into account the exchange rate depreciation used by the central bank as the short term objective, nominal exchange rate depreciation, $\Delta s$, is in the QPM is a weighted average of the 'policy set' depreciation path, $\Delta s^{\text {Tar }}$, and standard uncovered interest rate parity (UIP) implied depreciation, $\Delta s^{U I P}$ :

$$
\Delta s_{t}=w^{U I P} \Delta s_{t}^{U I P}+\left(1-w^{U I P}\right) \Delta s_{t}^{T a r}
$$

where $1-w^{U I P}$ is the weight of exchange rate depreciation target set by the central bank, which then reflect the tightness of the control over the exchange rate. The target depreciation is set by the central bank conditional on several inputs and is the following:

$$
\Delta s_{t}^{T a r}=\left(\Delta \bar{z}_{t}+\pi 4_{t}^{T a r}-\pi 4_{t}^{E X}\right)-f_{12} \pi 4_{t+1}^{D e v}-f_{22} \hat{z}_{t}+\varepsilon_{t}^{\Delta s^{T a r}},
$$

where $\pi 4^{T a r}$ is the inflation target for Rwandan year-on-year inflation and $\pi 4_{t}^{E X}$ is foreign inflation. The target rate of depreciation is given by country fundamentals, consistent with the equilibrium exchange rate depreciation rate, $\Delta \overline{\mathrm{z}}$, and domestic and foreign inflation differential (the first term in the brackets). The central bank might deviate from the equilibrium path of depreciation depending on inflation pressures coming from the exchange rate valuation as measured by the real exchange rate gap, $\hat{z}$, and expected deviation of domestic inflation from its target, $\pi 4_{t+1}^{D e v}$, and the expected inflation deviation from the target defined as the following:

$$
\pi 4_{t+1}^{D e v}=E_{t} \pi 4_{t+1}-E_{t} \pi_{t+1}^{T a r}
$$


The last term in (18), $\varepsilon^{\Delta s^{T a r}}$, is a policy shock in terms of setting the nominal depreciation target. 17

The UIP-implied depreciation in (17) is determined by the modified UIP condition as in Musil et al (2018), where the expected exchange rate is partly forward and partly backward-looking:

$$
\begin{gathered}
s_{t}^{U I P}=e_{1} E_{t} S_{t+1}+\left(1-e_{1}\right)\left(S_{t-1}+\frac{2}{4}\left(\Delta \bar{z}_{t}+\pi 4_{t}^{T a r}-\overline{\pi 4}_{t}^{*}\right) \pm \ldots\right. \\
\ldots-\left(\frac{i_{t}}{4}-\frac{i_{t}^{U S}}{4}-\frac{p r e m_{t}}{4}\right)+\varepsilon_{t}^{S},
\end{gathered}
$$

where prem is the country risk premium, and $E_{t} s_{t+1}$ is the model-consistent nominal exchange rate expected at time $t$ to take place at $t+1$. Backward looking agents take the last observation of the exchange rate and update it by the equilibrium rate of the nominal exchange rate depreciation, which equals the rate of the long-run (equilibrium) real exchange rate depreciation, $\Delta \bar{z}$, adjusted by the differential of domestic and foreign inflation objectives $\pi 4_{t}^{T a r}-\bar{\pi}_{t}^{*}$. Because the effective foreign sector is approximated by two large economies of the US and Eurozone, the foreign inflation objective is defined based on inflation objectives for these economies and is expressed in US equivalent with the equilibrium exchange rate depreciation of USD vis-à-vis EUR, $\Delta \overline{\bar{s}} \frac{u s d}{\operatorname{eur}}$ :

$$
\overline{\pi 4}_{t}^{*}=w^{U S} \cdot \overline{\pi 4}_{t}^{U S}+\left(1-w^{U S}\right) \cdot\left(\overline{\pi 4}_{t}^{E Z}+\Delta \bar{s}_{t}^{u s d / e u r}\right)
$$

The foreign interest rate $i^{U S}$ used in (20) is the US rate.

\section{Policy interest rate}

The policy interest rate, $i^{M P}$, is set according to a forward-looking policy rule ${ }^{18}$ :

$$
i_{t}^{M P}=g_{1} i_{t-1}^{M P}+\left(1-g_{1}\right)\left(i_{t}^{\text {Neutral }}+g_{2} E_{t} \pi 4_{t+1}^{\text {Dev }}+g_{4} \hat{y}_{t}^{\text {nagr }}\right)+\varepsilon_{t}^{i^{M P}},
$$

where $E_{t} \pi 4_{t+1}$ is expected year-on-year inflation in time $t+1$ based on information at time $t$, $\pi 4^{T a r}$ is the inflation target, and $i^{\text {Neutral }}$ is the neutral level of the policy interest rate consistent with expected inflation and economy operating at a potential non-agricultural output and $\varepsilon_{t}^{i^{M P}}$ is the policy shock in terms of the interest rate controlled by the central bank.

\footnotetext{
${ }^{17}$ Clearly, according to (18) there can be only temporary deviations from the rate of nominal depreciation consistent with the equilibrium rate of real depreciation and the inflation differential. Such deviations are meant to help convergence of the inflation and the real exchange rate to their target or equilibrium levels respectively.

${ }^{18}$ In the QPM for Rwanda the interest rate used as a policy rate is the weighted by the volumes average rate in REPO and reverse REPO operations, which the BNR conducts when managing systems' aggregate liquidity. This rate often deviated from the announced policy rate, which was diminishing the relevance of the latter as of the one indicating policy actions, and for this reason we use the rate in REPO transactions as a policy rate in the model.
} 
The short-term money market rate is defined in the model as the sum of the policy interest rate and a premium:

$$
i_{t}=i_{t}^{M P}+\operatorname{prem}_{t}^{I B} .
$$

The premium, prem $^{I B}$, follows AR processes with non-zero steady state prem $_{S S}^{I B}$ :

$$
\operatorname{prem}_{t}^{I B}=\rho^{\text {prem }^{I B}} \operatorname{prem}_{t-1}^{I B}+\left(1-\rho^{\text {prem }^{I B}}\right) \text { prem }_{s S}^{I B}+\varepsilon_{t}^{\text {prem }^{I B}},
$$

and $\varepsilon_{t}^{\text {prem }}{ }^{I B}$ indicating the shock to the premium. This premium then captures relatively persistent deviations of the short-term market rates from the policy rate amidst irregularities in the shortterm markets and liquidity management framework.

The real interest rate for the rate in (22) is

$$
r_{t}=i_{t}-E_{t} \pi 4_{t+1}
$$

and the gap component of it is defined as

$$
\hat{r}_{t}=r_{t}-\bar{r}_{t}
$$

and enters the real monetary condition index in (3).

\section{Fiscal block}

Effects of fiscal policy on Rwandan economic developments are captured by the fiscal impulse. The impulse enters the aggregate non-agricultural demand equation (3). The fiscal impulse is defined as a sum of changes in the cyclically-adjusted deficit, $\Delta d f 2 y^{c a d j}$, and in exceptional expenditures, $\Delta e e 2 y$ :

$$
\operatorname{fimp}_{t}=\Delta d f 2 y_{\mathrm{t}}^{c a d j}+\Delta e e 2 y_{t}
$$

All the above variables in (26) are ratios to nominal GDP. Exceptional expenditures are considered separately from budget deficits in the model, because of their structural nature and thus they directly enter the definition of fiscal impulse in the QPM. ${ }^{19}$

The cyclically-adjusted deficit $d f 2 y^{c a d j}$ is determined in the model via adjusting the total deficit $d f 2 y$ by its cyclical component $d f 2 y^{c}$, which gives rise to the following equation:

\footnotetext{
${ }^{19}$ After consultations with fiscal experts from the Ministry of Finance and Economic Development, exceptional expenditures (mostly expenditures on post-genocide relief projects) were assumed as having no cyclical part, i.e. no automatic stabilization component. Hence, they have been excluded from the rest of expenditures to avoid decomposing them into cyclical and structural parts. However, exceptional expenditures are "added back" when the fiscal impulse is defined in the model in terms of cyclically-adjusted deficit.
} 


$$
d f 2 y_{t}=d f 2 y_{t}^{c}+d f 2 y_{t}^{c a d j}
$$

while the share of cyclical component of the deficits moves with the business cycle:

$$
d f 2 y_{t}^{c}=d_{1} \hat{y}_{t}^{\text {nagr }}
$$

The cyclically-adjusted deficit to GDP ratio is an AR process, which describes convergence to the steady-state ratio of the fiscal deficit $d f 2 y_{s s}^{c a d j}$ in the QPM:

$$
d f 2 y_{t}^{c a d j}=\rho^{d f 2 y^{c a d j}} d f 2 y_{t-1}^{c a d j}+\left(1-\rho^{d f 2 y^{c a d j}}\right) d f 2 y_{s s}^{c a d j}+\varepsilon_{t}^{d f 2 y^{c a d j}} .
$$

As it is often the case in practice, fiscal data are available at annual frequency. Therefore, the model includes annual observed measures of such variables and variables at the quarterly frequency are unobserved and estimated with the Kalman filter using the observed data and the model.

\section{E. Aid}

Rwandan economy experiences substantial concessional borrowing and foreign aid inflows. The aid flows channeled to the national economy mainly through the public accounts and hence are reflected in the government budget data. Given the specific nature of such flows and the fact that they originate from abroad, we treat aid as a separate variable and hence aid is not included in the total and cyclically-adjusted deficit, and in the fiscal impulse. In order to account for real effects of aid inflows on Rwandan economy, we decompose the ratio of aid to nominal GDP a $\widehat{2 y}$ into gap $\widehat{\mathrm{a} 2 \mathrm{y}}$ and trend $\overline{\mathrm{a} 2 \mathrm{y}}$ components that are AR processes in the QPM:

$$
\begin{gathered}
\widehat{a 2 y_{t}}=\rho^{\overline{a 2 y}} \widehat{a 2 y_{t-1}}+\varepsilon_{t}^{\overline{a 2 y}}, \\
\overline{a 2 y}_{t}=\rho^{\overline{a 2 y}} \overline{a 2 y}_{t-1}+\left(1-\rho^{\overline{a 2 y}}\right) \overline{a 2 y}_{s s}+\varepsilon_{t}^{\overline{a 2 y}} .
\end{gathered}
$$

The change in the gap component enters the non-agricultural output gap equation (3).

\section{F. External sector}

The US and the Eurozone variables are used to introduce an effective foreign block in the Rwanda QPM approximating global economy. Effective foreign inflation and foreign output gap are weighted averages of respective variables for the US and the Eurozone. Namely, foreign effective inflation, $\pi^{*}$, is modeled as follows:

$$
\pi_{t}^{*}=w^{U S} \pi_{t}^{U S}+\left(1-w^{U S}\right)\left[\pi_{t}^{E Z}+s_{t}^{\frac{U S D}{E U R}}\right]
$$


where $\pi^{U S}$ is q-o-q US headline inflation, $\pi^{E Z}$ is q-o-q Eurozone headline inflation, and $w^{U S}$ is the share of the US which is used as a proxy also for the rest of the world. Finally, $s^{\frac{U S D}{E U R}}$ is the cross-exchange rate. Similarly, the foreign effective output gap is the weighted average of two gaps:

$$
\hat{y}^{*}=w^{U S} \hat{y}_{t}^{U S}+\left(1-w^{U S}\right) \hat{y}_{t}^{E Z}
$$

Foreign inflation rates in (32), output gaps in (33) and trends in foreign output are simple AR processes in the model, and the cross-exchange rate USD/EUR is a martingale process (see appendix B). The foreign interest rate is approximated by the US rate this is the only foreign rate, which is included in the Rwanda QPM in the UIP equation. Clearly, equations for foreign variables are not in the structural, but rather in a univariate reduced form. These equations however are not used to produce forecast of foreign variables, when the QPM is applied in macroeconomic and policy projections by the BNR during the forecasting rounds: rather, the forecasts for foreign variables and commodity prices are exogenized and projections from external sources like WEO and others are used for such variables instead. Hence, the projections of domestic variables are "conditioned" on projections of foreign variables available from external sources.

The limited number of countries used in the model to approximate the effective external sector is by purpose as practical application of the QPM for projections requires collecting forecasts for all external variables. Therefore, there is a trade-off when expanding the model further by adding more countries or regions.

\section{G. Money demand}

The model also includes the money demand block, which describes demand for M3 aggregate and reserve money. Although money aggregates do not enter any equation out of the money demand block, reserve and broad money growth are used by authorities as indicator variables about monetary stance. ${ }^{20}$

The money demand block starts with demand for nominal broad money, $m 3^{N}$. The demand is given by demand for real money, $m 3$, adjusted by prices, $c p i$ :

$$
m 3_{t}^{N}=m 3_{t}+c p i_{t}
$$

Real broad money demand is further broken down to a trend, $\overline{m 3}$, and a gap, $\widehat{m 3}$. In line with standard demand for real money balances, holding of money depends on real economic activity, namely the real non-agricultural output gap, and the real interest rate gap. The real interest rate gap measures costs of money holding:

\footnotetext{
${ }^{20}$ Incorporating money demand in the QPM style models is discussed for example in Andrle et al (2013a).
} 


$$
\widehat{m 3}_{t}=c_{1} \widehat{m 3}_{t-1}+\left(1-c_{1}\right)\left(c_{2} \hat{y}_{t}^{\text {nagr }}-c_{3} \hat{r}_{t}\right)+\varepsilon_{t}^{\widehat{m 3}},
$$

where $\epsilon^{\widehat{m 3}}$ is the broad money demand shock.

Equilibrium changes in demand for broad money are in line with country fundamentals, i.e. potential GDP growth adjusted by changes in velocity, $\Delta v$ :

$$
\Delta \overline{m 3}_{t}=\rho^{\overline{m 3}} \Delta \overline{m 3}_{t-1}+\left(1-\rho^{\overline{m 3}}\right)\left(\Delta \bar{y}_{t}-\Delta v_{t}-c_{4}\left(\bar{r}_{t}-\bar{r}_{t-1}\right)\right)+\varepsilon_{t}^{\Delta \overline{m 3}},
$$

where $\epsilon^{\Delta \overline{m 3}}$ is the shock to equilibrium real broad money demand growth. Changes in velocity is assumed to follow an AR process:

$$
\Delta v_{t}=\rho^{\Delta v} \Delta v_{t-1}+\left(1-\rho^{\Delta v}\right) \Delta v_{s s}+\varepsilon_{t}^{\Delta v},
$$

where $\epsilon^{\Delta v}$ is a velocity shock.

Demand for reserve money, $r m$, is derived from the broad money demand adjusted by money multiplier, mult:

$$
r m_{t}=m 3_{t}+\text { mult }_{t}
$$

Money multiplier as observed in the data hovers along a long term trend. This is captured in the model by broking down the multiplier to a gap, $\widehat{\text { mult }}$, and a trend growth, $\Delta \overline{\text { mult }}$ :

$$
\Delta \overline{\text { mult }}_{t}=\rho^{\overline{\text { mult }}} \Delta m u l t_{t-1}+\left(1-\rho^{\overline{m u l t}}\right) \Delta \overline{m u l t}_{s s}+\varepsilon_{t}^{\Delta \overline{m u l t}},
$$

and

$$
\widehat{\text { mult }}_{t}=\rho \widehat{\text { mult }}_{t-1}+\varepsilon_{t} \widehat{\text { uult }} .
$$

\section{Model Calibration and Properties}

The model is calibrated to match the policy transmission mechanism and particularities of Rwandan economy. The first subset of model parameters describes the steady state. Another subset consists of equation coefficients, namely those in structural equations for domestic variables and in reduced form equations for foreign variables and long-term trends. Finally, the standard deviations of shocks need to be calibrated. Calibration of the steady state parameters is usually informed by in-sample averages of respective variables, judgments about changes or breaks in such averages over the historical period, in-sample forecasting performance of the model and by values of policy objectives, for example, the inflation target. Other published models, historical data and evaluating properties of the model by means of impulse response analysis help calibrating coefficients in the QPM equations. Calibration of coefficients in the reduced form equations is also guided by matching the observed data and ensuring reasonably smooth longterm trends. Standard deviations of shocks are calibrated accounting for the observed variance in the data, ensuring that unobserved and estimated trends in the model in general are less volatile 
than gaps and observed variables and by allowing meaningful relationship between variables consistent with macroeconomic intuition. ${ }^{21,22}$ Model responses to key shocks are discussed in this section and further calibration checks and tests are presented in the next section.

\section{Figure IV.1: Cost-push shock - Core inflation}
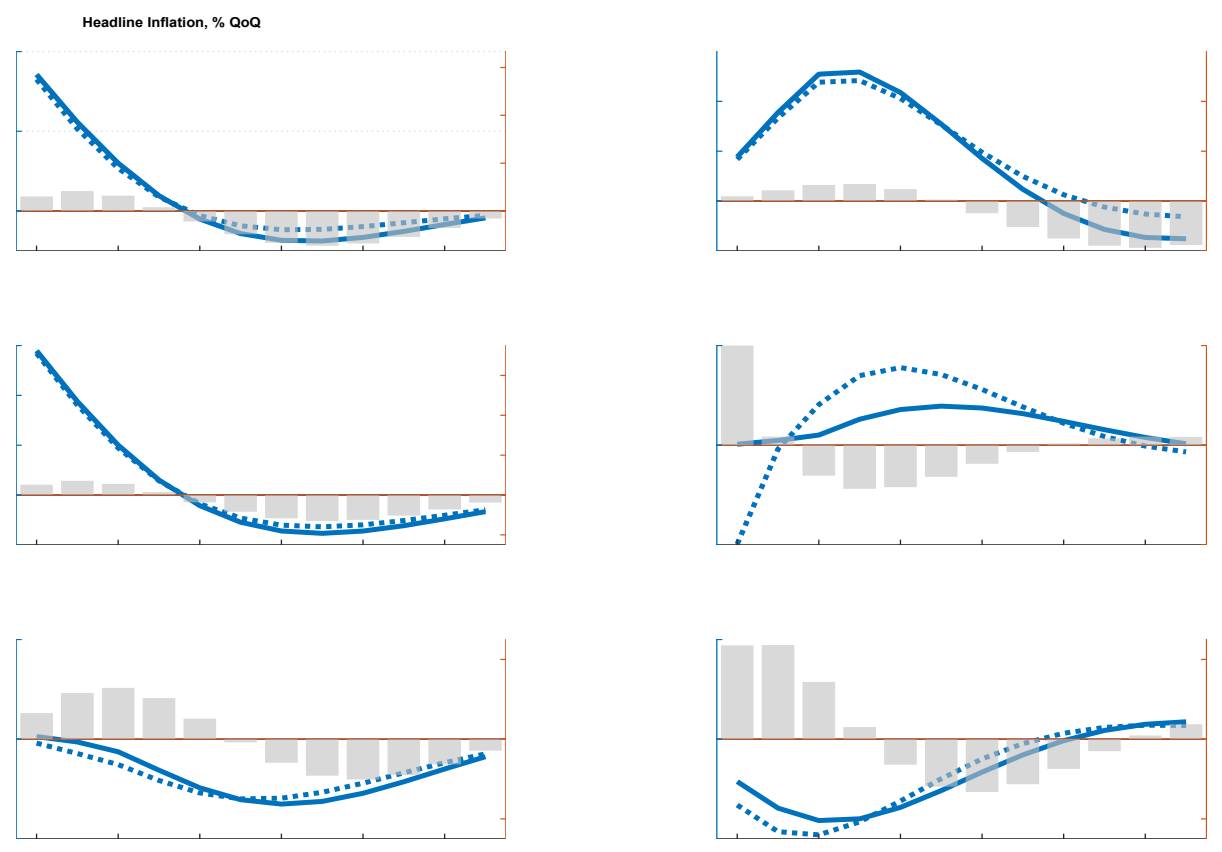

Source: Authors' calculations

Note: Each plot presents impulse response of a variable in the title with the solid line consistent with the model for Rwanda and the dashed one consistent with the FlexER model variant with a floating exchange rate. Bars (right axis) are the differences between the IRs for the QPM for Rwanda and the FlexER model.

In order to demonstrate properties of the Rwanda QPM and evaluate policy implications we present impulse responses to several key shocks. These include the cost-push (supply) shock and the aggregate demand shock to non-agricultural output. Additionally, we report responses to the shock to agricultural production. All impulse responses are compared with those for the alternative model of the same structure and calibration, but with floating exchange rate. This model is labeled below as a FlexER version of the model. Responses to shocks are reported as deviations from the steady-state.

\footnotetext{
${ }^{21}$ Calibrated values of steady-state parameters and coefficients in structural equations are in Annex B. The remaining parameters, including standard deviation of shocks can be provided upon request.

${ }^{22}$ For example, allowing for the standard deviation of the cost-push shock in the inflation equation (Philips curve) which is too high, may lead to the estimate of the output gap which is largely uninformed by inflation developments. This would contradict macroeconomic prior that cost develop with the business cycle and hence the output gap that we estimate must be driving inflation.
} 
We report impulse responses to key structural shocks to highlight model properties and monetary policy reaction to stabilize the economy and fulfil the price stability objective. Figure IV.1 shows the response of Rwandan economy to 1 p.p. increase in core inflation.

The increase in the core pushes up the headline inflation. The central bank raises the policy interest rate and keeps nominal exchange rate depreciation unchanged initially. Given the stable nominal exchange rate and increasing domestic prices, the real exchange rate appreciates and a negative real exchange rate gap opens, which leads to tightening of real monetary conditions. The economy turns to operating below capacity as is indicated by a negative non-agricultural output gap. As a result, disinflationary pressures are created on both domestic and imported costs sides, inflation gradually declines below the target and the central bank allows for higher nominal exchange rate depreciation in order to mitigate some undershooting of the inflation target.

A demand shock represented by 1 p.p. increase of the non-agricultural output gap, Figure IV.2, raises inflation.

Figure IV.2: Demand shock - non-agricultural output gap
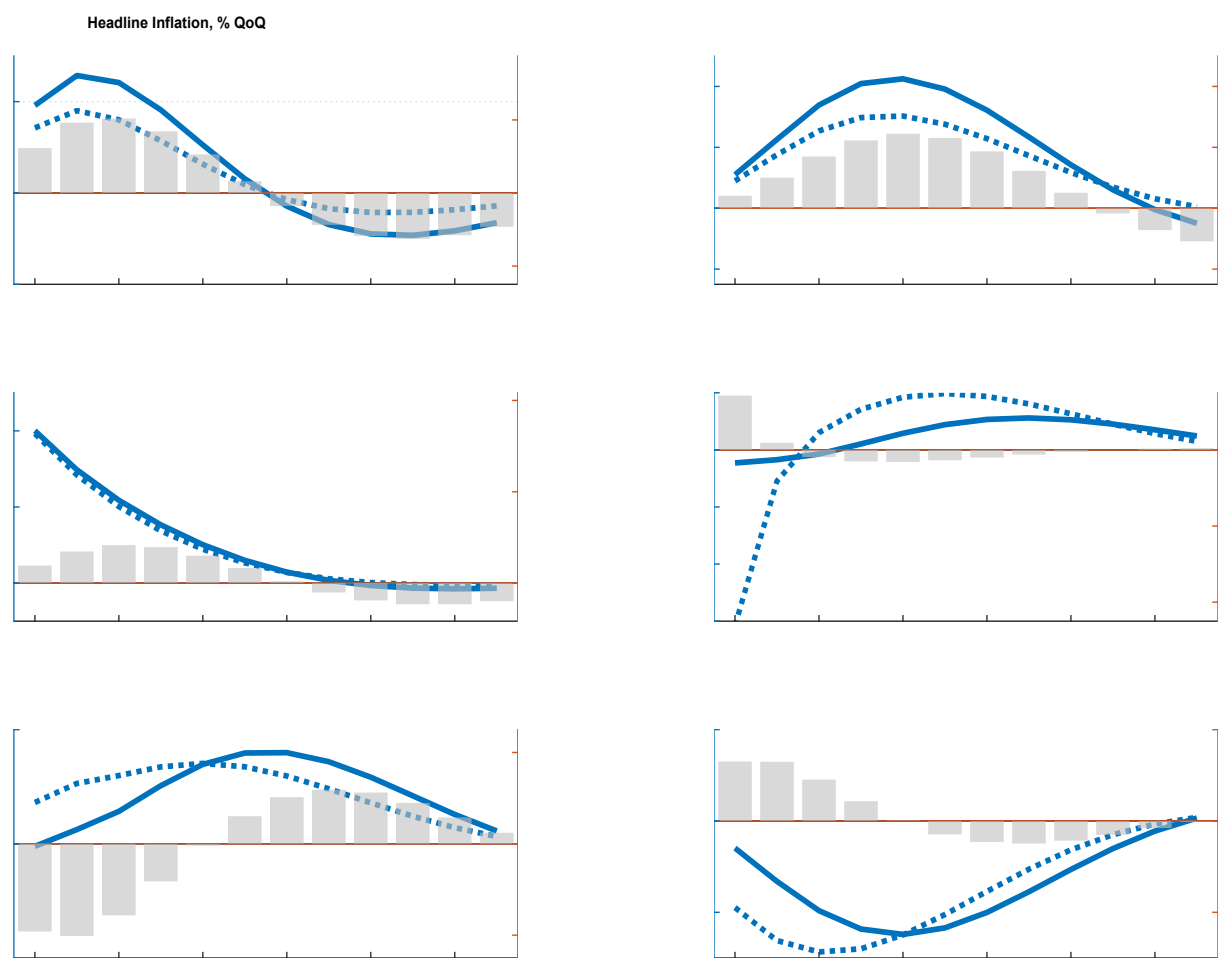

Source: Authors' calculations

Note: Each plot presents impulse response of a variable in the title with the solid line consistent with the model for Rwanda and the dashed one consistent with the FlexER model variant with a floating exchange rate. Bars (right axis) are the differences between the IRs for the QPM for Rwanda and the FlexER model. 
The central bank reacts by increasing the monetary policy rate and by allowing for marginally slower nominal depreciation. The temporarily overvalued real exchange rate along with the real interest rate above its equilibrium level lead to tight monetary conditions. Tighter conditions counteract demand pressures and the normal level of capacity utilization is gradually restored. Overvalued in real terms domestic currency and gradually subsiding domestic cost pressures allow for slowing inflation and bringing it back to the target.

One more shock used to demonstrate properties of the QPM is a 1 p.p. increase in agricultural production, Figure IV.3.

Figure IV.3: Good harvest - shock to the agricultural output
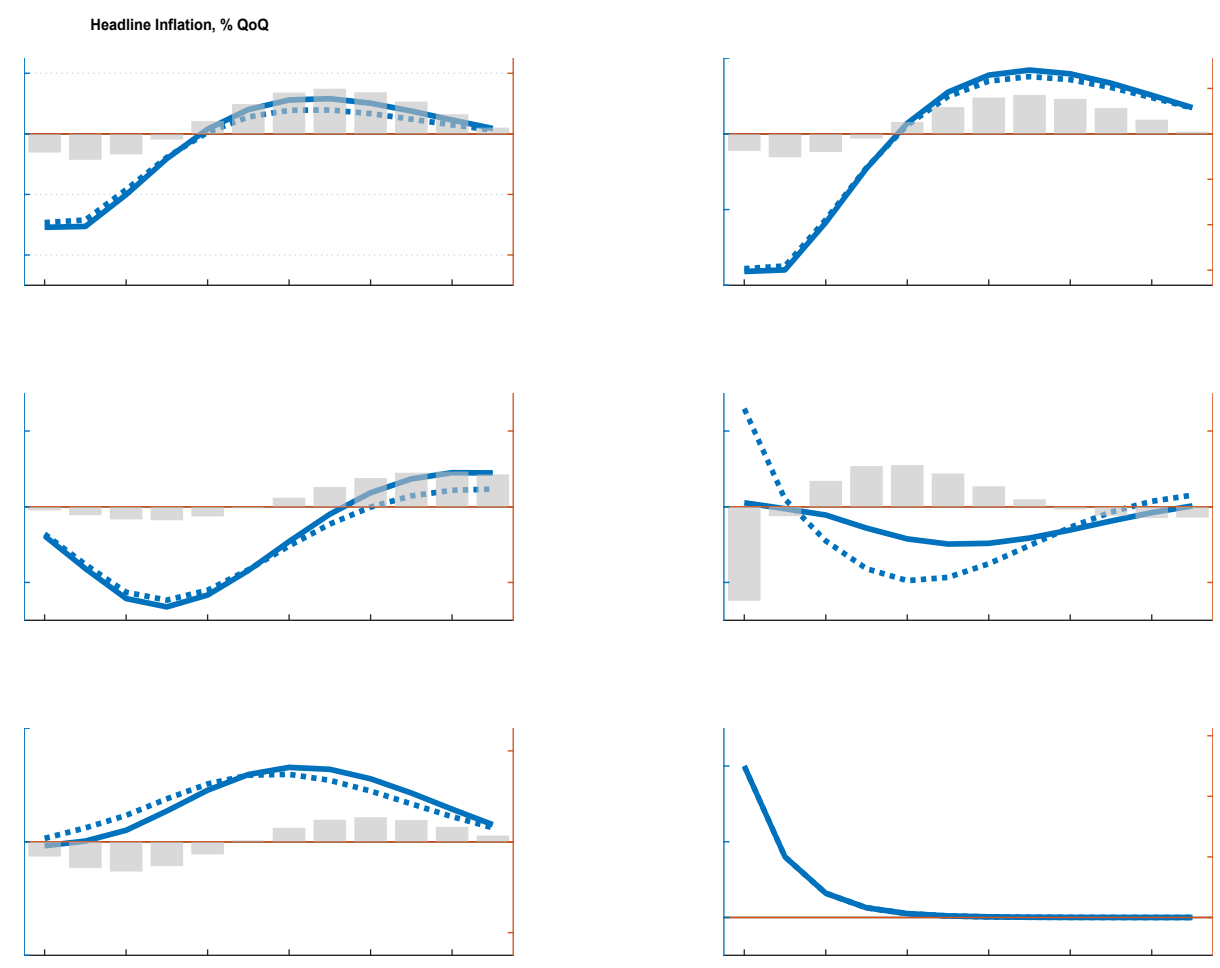

Source: Authors' calculations

Note: Each plot presents impulse response of a variable in the title with the solid line consistent with the model for Rwanda and the dashed one consistent with the FlexER model variant with a floating exchange rate. Bars (right axis) are the differences between the IRs for the QPM for Rwanda and the FlexER model.

A good harvest pushes down food prices and consequently headline inflation drops below the target. In response to decelerating inflation, the central bank cuts the policy rate, while keeping nominal exchange rate depreciation unchanged initially. Because domestic prices decline, the real exchange rate depreciates and becomes temporarily undervalued, which creates inflationary pressures. In the non-agricultural sector, capacity becomes utilized in excess of the normal level 
due to accommodative monetary stance. Both, domestic and imported costs of production pick up and help to bring inflation back to the target.

Because the BNR does some market interventions to smoothen the exchange rate volatility in addition to using policy interest rate as an operational target, the policy transmission mechanism in Rwanda differs from that in the policy framework with a flexible exchange rate. As is highlighted by the comparison of the Rwanda QPM impulse responses with those for the hypothetical model with the flexible exchange rate, the variability of exchange rate in the current BNR policy framework is limited for the shocks analyzed above, but at the cost of a higher variability of inflation, real output and, consequently, higher variability of the interest rates. The lower degree of exchange rate variability is due to potential trade-off between stabilizing inflation vis-à-vis stabilizing the exchange rate as is implied by the structure of the exchange rate targeting rule (18). ${ }^{23}$ For example, such a tradeoff materializes in the case of the demand shock as the actual and expected inflation exceed the target and, which pushes towards faster targeted rate of depreciation. At the same time, the currency becomes undervalued in real terms - positive real exchange rate gap in (18) - which limits the extent of targeted depreciation in response to the demand shock. Hence, the exchange rate is smoothed and its role in promoting macroeconomic stabilization is more limited than it otherwise could be if the exchange rate was flexible. Notably, the exchange rate in the demand shock scenario appreciates only when inflation picks up some 6 quarters after the shock and overshoots the target: at this point the exchange rate is still undervalued and both factors - the inflation deviation and the real exchange gap - point towards slower targeted depreciation, which helps macro stabilization. We can imagine that to avoid the tradeoff and increase the macroeconomic stabilization role of the exchange rate the depreciation target in (18) can be made responding only to inflation deviation from the target. However, the qualitatively similar effect can be achieved when the exchange rate flexibility is increased, and it responds more to the interest rate differential.

Effects of higher government expenditures on Rwandan economy are demonstrated by a positive fiscal impulse, Figure IV.4. The positive fiscal impulse is simulated as 1 percent increase of structural budget deficit along with 1 percent increase of exceptional expenditures, both over the 1 year horizon. As a result of shocks, the fiscal impulse is positive peaking at 2 percent at the start of simulation. The positive fiscal impulse boosts the economic activity and a positive non-agricultural output gap starts to open. The higher demand generates inflationary pressures and the central bank

\footnotetext{
${ }^{23}$ There is the trade-off between inflation and exchange rate variability implied by equation (18) unless there is positive correlation between inflation deviation from the target and the real exchange rate gap implied by, for example a shock to the country risk premium or an UIP shock.
}

CInternational Monetary Fund. Not for Redistribution 
tightens monetary policy. In response to tightening, the nominal exchange rate appreciates initially before it turns to depreciation on the back of rising domestic price level. Given the model definition of the fiscal impulse as the change of structural deficit on GDP, the fiscal impulse becomes negative in the second year of the simulation. The negative fiscal impulse enforces monetary tightening, pushing the non-agricultural output gap to be negative. However, the total effects of the shocks are positive in terms of GDP, given the assumption of a positive fiscal multiplier.

Consistently with a positive fiscal impulse, the government deficit on GDP widens. However, it is important to note that the model does not encompass debt and its endogenous stabilization. As described in the previous chapter, the model is designed to re-take external fiscal projections from the Ministry of Finance and Economic Planning, assuming that planned deficits are sustainable. Therefore, nominal exchange rate depreciation observed in the simulation of a positive fiscal impulse does not reflect rising deficit but the monetary policy response and it assumes implicitly sustainability of the debt. To simulate a debt path threating sustainability would require the combination of the fiscal impulse with a shock increasing the country risk premium.

Figure IV.4: Positive fiscal impulse
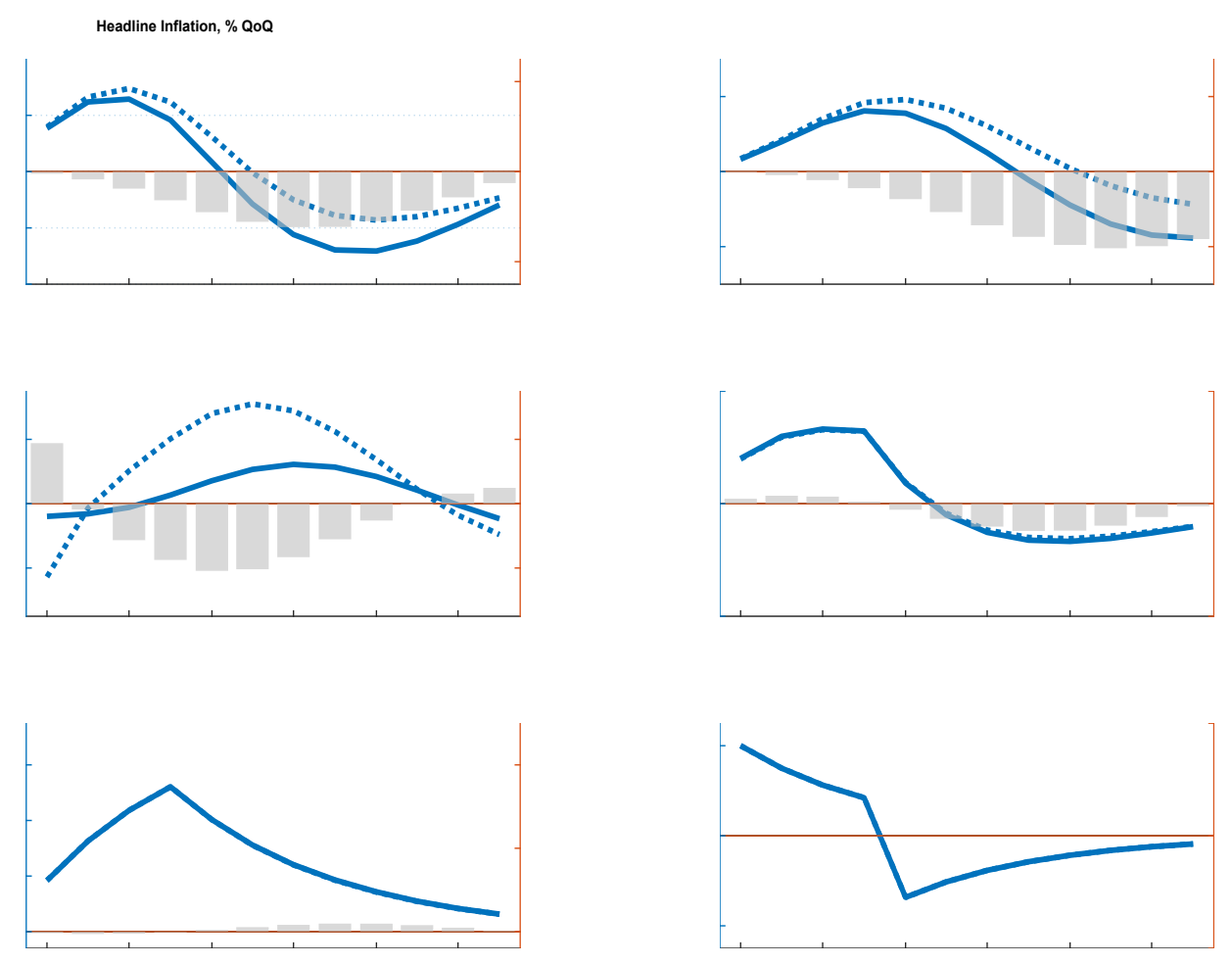

Source: Authors' calculations

Note: Each plot presents impulse response of a variable in the title with the solid line consistent with the model for Rwanda and the dashed one consistent with the FlexER model variant with a floating exchange rate. Bars (right axis) are the differences between the IRs for the QPM for Rwanda and the FlexER model. 
Similarly, aid inflows boost domestic demand, i.e. the non-agricultural gap. Figure IV.5 shows impulse response of key model variables experiencing aid inflows reaching 1 percent of GDP for the period of 1 year. The transmission of the shock and the monetary policy response are similar to the fiscal impulse previously described. However, it is worth of noticing that the variability of inflation is lower under the float compared to the current regime of exchange rate management. This is so as the free float does not restrict accommodation of the shock through the exchange rate depreciation.

Figure IV.5: Aid inflows shock
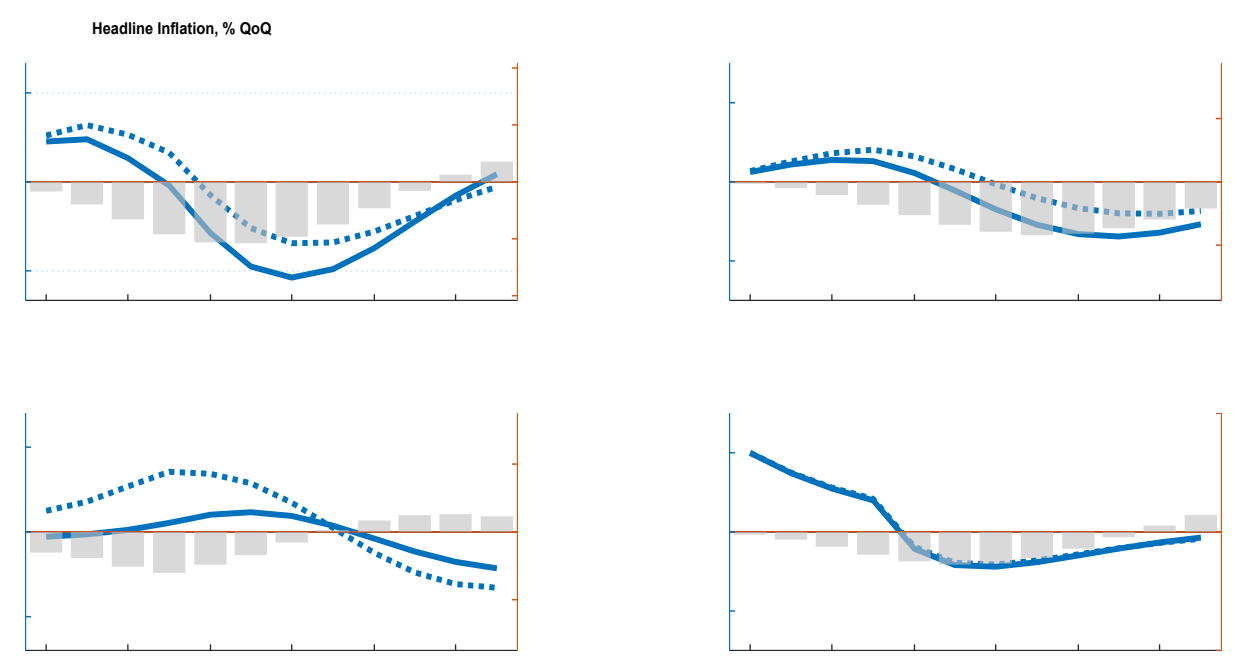

Source: Authors' calculations

Note: Each plot presents impulse response of a variable in the title with the solid line consistent with the model for Rwanda and the dashed one consistent with the FlexER model variant with a floating exchange rate. Bars (right axis) are the differences between the IRs for the QPM for Rwanda and the FlexER model.

\section{MODEL SIMULATIONS AND HISTORICAL DATA INTERPRETATION}

We apply the model in several simulation exercises: (i) in-sample simulations are used to check the ex-post forecasting ability of the model, (ii) filtration of the historical data and decomposition of observed variables into structural shocks are held to assess historical macroeconomic developments. 


\section{In-sample simulations}

One of the signs that the model is calibrated reasonably well is that forecasts do not deviate systematically from the data and in contrast to macroeconomic intuition. It appears broadly to be the case for Rwanda QPM. ${ }^{24}$ We analyze in-sample projections starting from 2009Q1 and assume that all external (foreign) variables are known over the forecasting horizon. All other observed variables are known only until the quarter preceding every forecast realization over the next 8 quarters. No expert judgments are added in this exercise, although in practice this is often the case. Figure V.1 presents in-sample simulations where the dotted lines are model based forecasts 8quarters ahead and the solid blue line is the actual data.

Figure V.1: Model based simulations versus the actual data
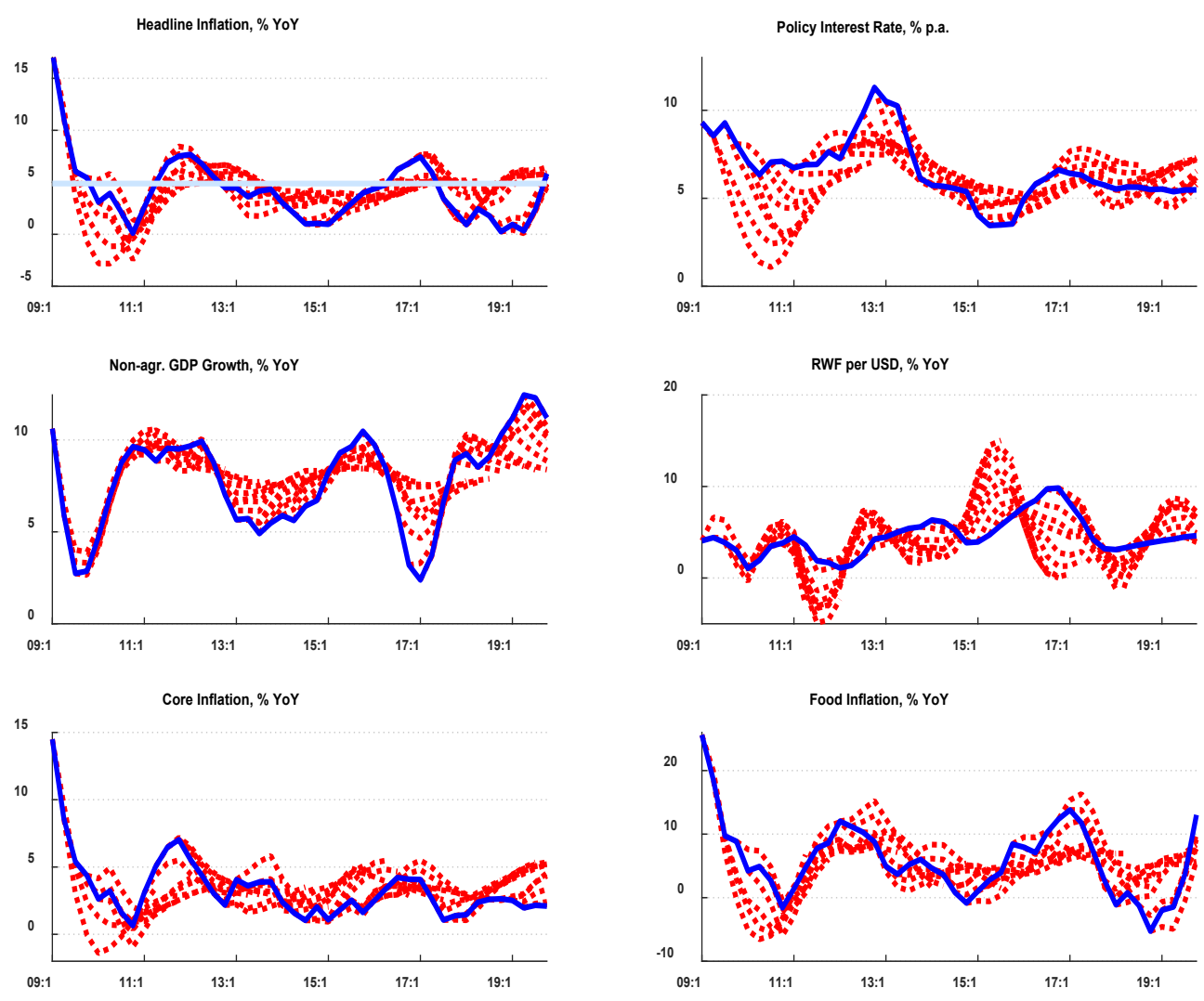

Source: Authors' calculations

\footnotetext{
${ }^{24}$ However, not all deviations of model-based forecasts from the data can be interpreted as imperfection of the model or of its calibration. Some deviations might be a result of policy mistakes or deviations of implemented policy from the model prescriptions. Therefore, deviations of in-sample forecasts from the data need to be carefully analyzed from this perspective as well.
} 
Model based forecasts seem to match reasonably well the actual data. This is the case for the period of 2009-2013, in particular. The model-based forecasts in 2014-2016 predict higher than actual headline and core inflation and in line with that also higher than actual nominal interest rate. Inflationary pressures in model forecasts come from faster nominal exchange rate depreciation compared to that in the actual data as the model predicts a higher country risk premium. The unobserved risk premium is estimated (filtered with KF) from the data: it peaked in early 2015 and sharply declined afterwards. ${ }^{25}$ This drop in the estimated premium is not predicted by the model in in-sample simulations, and hence implies faster than observed nominal depreciation. As a result, this faster predicted depreciation conditions inflation in in-sample simulations to be above the actual and closer to the inflation target of 5 percent. In order to additionally verify that it was indeed the issue with the premium and to cross-check the calibration of the exchange rate pass-through in the model, we repeat the in-sample simulation assuming that the nominal exchange rate dynamics along with the premium is known, see Figure V.2.

Figure V.2: Model based simulations versus the actual data
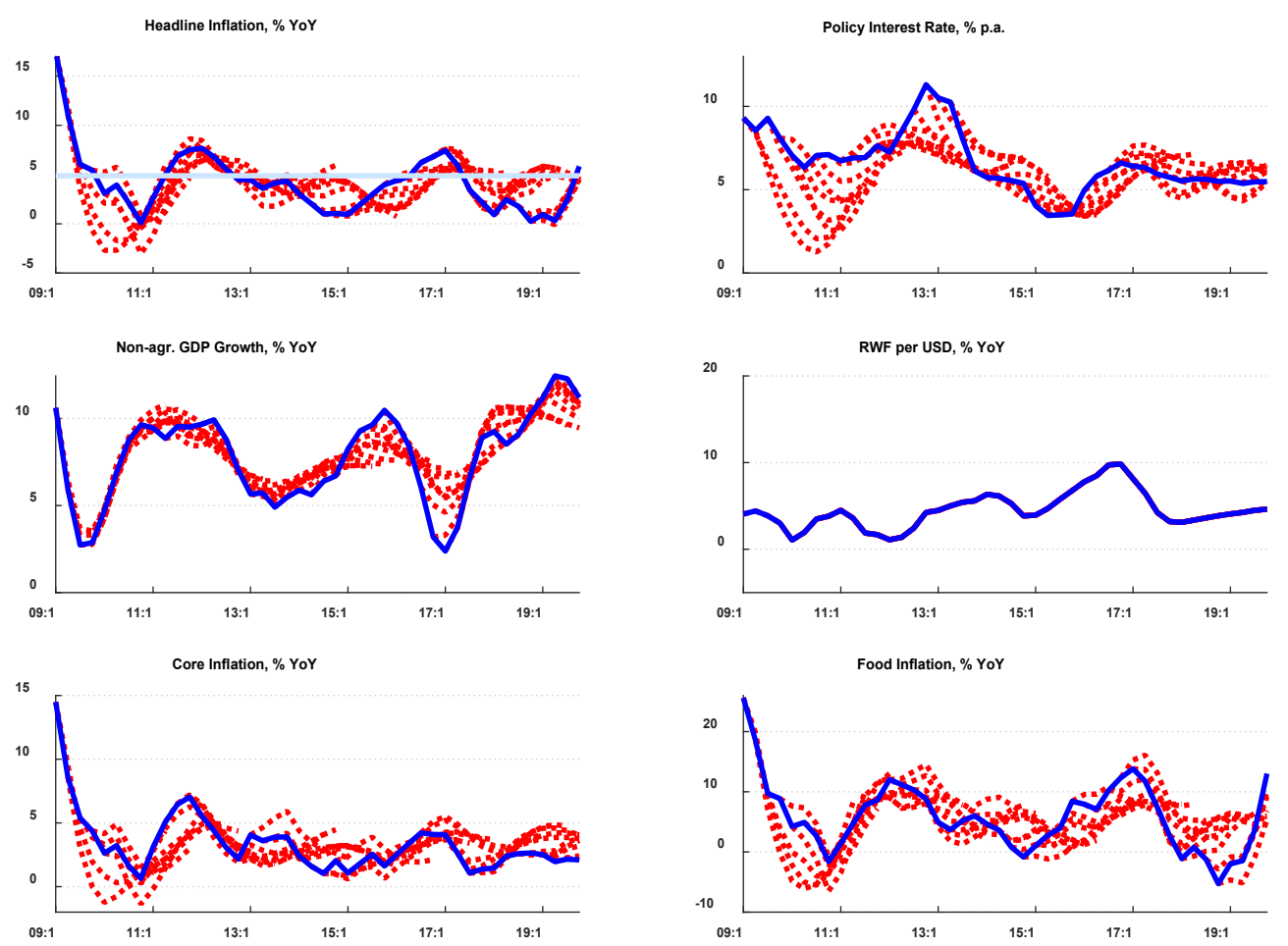

Source: Authors' calculations

\footnotetext{
25 The premium started to increase in 2013, peaking in 2015. The period of its increase coincided with high U.S. Treasury bond yields and the phenomenon called the taper tantrum.
} 
When the premium and the exchange rate are conditioned in this way, projections for headline and core inflation are not upward biased as in 2014-2015. ${ }^{26}$ The remaining upward bias in projections of inflation over this period is caused by a more accommodative policy stance - lower level of the interest rate - that the model predicts in comparison to the actual stance during the period just before in 2014. Therefore, from this ex-post perspective, had the interest rates in 20122013 stayed lower, the actual inflation would have been closer to the model projections (and the benchmark of 5 percent) in 2014-2015. ${ }^{27}$

The projections for headline inflation also overshoot actual in the more recent period of 20182019. This is driven by the predicted high food and core inflation which did not take place actually. Food prices in Rwanda significantly declined in the end of 2018 on the back of relatively good domestic harvests and despite rising world food prices. Similarly, the core inflation was surprisingly low during 2018-2019 while model predicts rising inflation. Several macroeconomic forces conditioned such an outcome. Disinflationary shocks during this period have been identified applying the model in the filtration exercise (see discussion in the next subsection). Starting from 2017, the model predicts a more accommodative monetary policy than has actually taken place and has contributed to actual inflation, which, in turn, was lower than predicted rates and lower than the benchmark. Limited food inflation constrained core inflation via the effect of relative prices.

Additionally, we compare RMSFEs for our model and for the random walk (RW) benchmark to further evaluate forecasting ability of the QPM for Rwanda over the horizons from 1 to 8 quarters (Table 1). Whenever the reported ratio is less than 1, it indicates that the QPM model outperforms RW for the respective variable and the forecasting horizon. Notably, QPM's forecasting performance is superior to that of RW for majority of key variables and forecasting horizons, the exception is the policy rate at short horizons and the nominal exchange rate depreciation at all horizons. We note however that both, the interest rate and the nominal depreciation are policy variables and thus in in-sample simulations they are assumed to be set by the model to deliver inflation back to the benchmark (target). Therefore, their comparison with the actual monetary policy setting might not be appropriate, if in the history the policy framework was less reliant on the interest rate steering.

\footnotetext{
${ }^{26}$ Assuming that the nominal exchange rate path is known also helps to improve in-sample forecasts of nonagricultural GDP growth which move closer to the actual data over the whole range.

${ }^{27}$ Therefore, from this ex-post perspective, if there was no such a hike in interest rates in 2012-2013, inflation would have been closer to the target in 2014-2015.
} 
Table 1: In-sample forecasting performance of the QPM vis-à-vis Random Walk (RW) benchmark during 2009Q1 - 2019Q4

\begin{tabular}{|l|c|c|c|c|c|c|c|c|}
\hline \multirow{2}{*}{\multicolumn{1}{|c}{ Variable }} & \multicolumn{7}{|c|}{$\begin{array}{c}\text { The ratio of RMSEs for QPM over RW, } \\
\text { for the forecast horizon quarters ahead }\end{array}$} \\
\cline { 2 - 10 } & $\mathbf{1 Q}$ & $\mathbf{2 Q}$ & $\mathbf{3 Q}$ & $\mathbf{4 Q}$ & $\mathbf{5 Q}$ & $\mathbf{6 Q}$ & $\mathbf{7 Q}$ & $\mathbf{8 Q}$ \\
\hline Headline CPI Inflation, YoY & 0.49 & 0.50 & 0.49 & 0.53 & 0.49 & 0.46 & 0.41 & 0.40 \\
\hline Core Inflation, YoY & 0.51 & 0.50 & 0.48 & 0.52 & 0.49 & 0.50 & 0.51 & 0.54 \\
\hline Food Inflation, YoY & 0.56 & 0.57 & 0.54 & 0.60 & 0.55 & 0.48 & 0.41 & 0.40 \\
\hline Policy Interest Rate & 1.34 & 1.32 & 1.14 & 1.04 & 0.97 & 0.91 & 0.83 & 0.71 \\
\hline Nominal Depreciation RWF/USD, YoY & 1.13 & 1.10 & 1.05 & 1.05 & 1.24 & 1.40 & 1.50 & 1.57 \\
\hline Real GDP Growth, YoY & 0.57 & 0.49 & 0.43 & 0.42 & 0.54 & 0.57 & 0.63 & 0.60 \\
\hline Real Non-agricultural GDP Growth, YoY & 0.40 & 0.34 & 0.31 & 0.33 & 0.39 & 0.45 & 0.48 & 0.50 \\
\hline
\end{tabular}

\section{Historical data filtration}

We exploit Kalman filtration (KF) to match the actual data with the model and to identify unobserved variables including structural shocks. Here, we present filtration outcomes in terms of unobserved variables driving inflation. Understanding factors shaping inflation dynamics, the output gap and the real exchange rate gap, is key for successful implementation of policy under the policy strategy focusing on price stability. Filtration outcomes help to compile a narrative about macroeconomic developments and inform policy actions. Estimates of unobserved gap variables obtained with KF can also be contrasted with alternative estimates and expert judgement to evaluate adequacy of the former, which in turn may shed additional light on whether model calibration need to be adjusted further.

Historical data filtration shows how real marginal costs shaped inflation dynamics. Figures V.3 and V.4 show core and food prices inflation along with the decomposition of corresponding real marginal costs. In both cases cost developments precede inflation dynamics.

Figure V.3 shows that the non-agricultural output gap, approximating domestic cost pressures, was mostly disinflationary over 2012-2019. This reflects a relatively moderate GDP growth compared to earlier periods. Low demand and domestic cost pressures were at times partially offset by relatively high costs of imports, as approximated by the positive real exchange rate gap, but on average the total costs constrained core inflation. In the more recent period of 2018-2019, the output has turned to be above the neutral level while a positive real exchange rate gap persisted. As a result, core Q-o-Q inflation towards the end of the historical sample started to increase gradually. 
Figure V.3: Core Inflation and Real Marginal Costs, \%

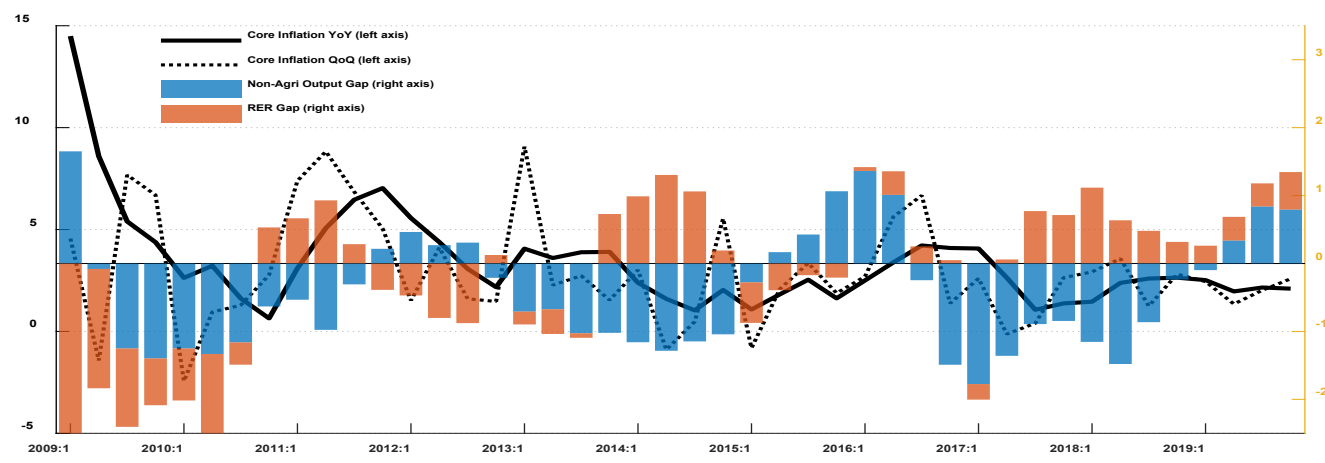

Source: Authors' calculations

Note: bars denote contributions to real marginal costs. Summing up bars gives total real marginal costs.

Fluctuations in local supply of agricultural products along with world food prices were the main factors driving highly volatile food price inflation in Rwanda, Figure V.4. The impact of other domestic costs approximated by non-agricultural output gap is comparably smaller. World food prices along with a good local harvest created substantial disinflationary pressures on food prices during 2016-2017 and pushed food price inflation down from its peak in the end of 2016. Although world food prices switched from disinflationary to inflationary pressures in 2018, food price inflation continued to be subdued, bringing the headline indicator close to the two percent lower bound of the interval around the inflation target. As the drag on costs diminished starting from the second half of 2018, the food price inflation has started to accelerate in 2019.

Figure V.4: Food Inflation and Real Marginal Costs, \%

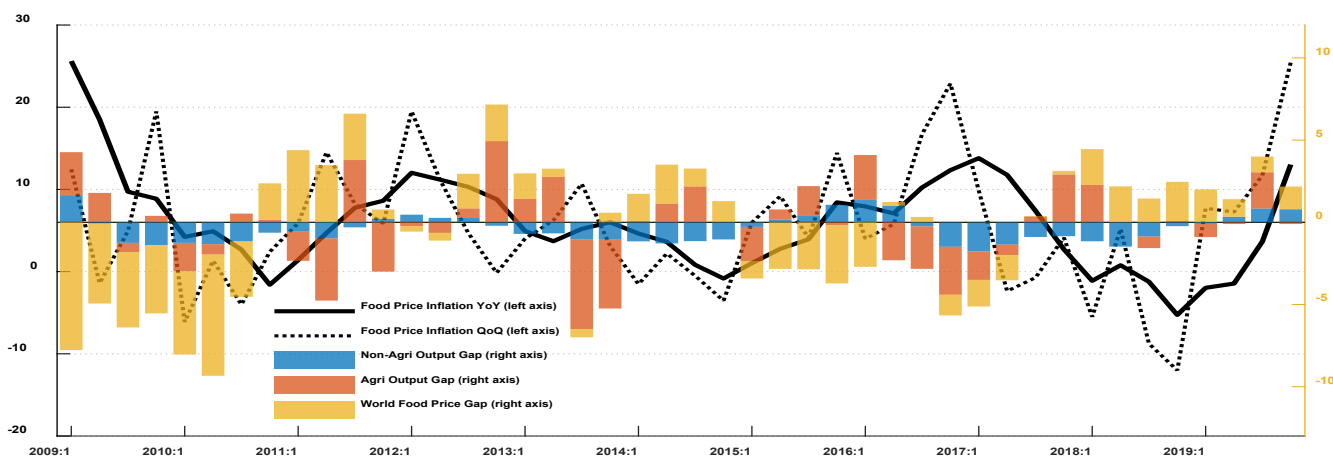

Source: Authors' calculations

\section{Historical decomposition to shocks}

Historical data decomposition to shocks provides another approach to checking model properties and calibration. The decomposition shows what structural shocks affected the dynamics of each variable over the historical period. The structural shocks come from the filtration of the data. To assess the model calibration and properties, the decomposition should help to see that (i) the dynamics of a variable is not driven solely by its "own" shock (for example inflation should not 
be solely explained by the cost-push shocks) and (ii) a macroeconomic story based on the decomposition matches experts' intuition and views on macroeconomic developments in the country during the analyzed period.

Decomposition of y-o-y core and food price inflation to structural shocks in the model is presented in Figures V.5 and V.6. Both core and food price inflation are plotted as deviations from their respective implicit targets. ${ }^{28}$ The decomposition for core and food inflation suggests that the dynamics of these subcomponents has been substantially impacted by external shocks. ${ }^{29}$ World food and oil prices sharply declined in the wake of world financial crisis in 2009-2010 pushing down inflation in the US and the EMU. As a result, core inflation in Rwanda also dropped despite accommodative monetary policy. External development was relatively neutral with respect to Rwandan core inflation in the period of 2011-2015. Core inflation deviations from the implicit target were driven mostly by cost push (supply) shocks. Cost push shocks were inflationary in most of 2011-2013 before creating disinflationary pressures in 2014-2016. During the same period, domestic demand and external shocks worked in the opposite direction and supported inflation. Foreign economic developments, mainly oil prices, along with low domestic demand, the non-agricultural demand shocks, created constrained inflation in Rwanda in 2017-2019. The effect of foreign developments and low domestic demand was only partly offset by the proinflationary effect of cost-push shocks. Although such disinflationary effects gradually faded in

\footnotetext{
${ }^{28}$ The benchmark (target) is announced for headline inflation only. The "implicit" target for the respective inflation component here means the benchmark for the headline less the historical average of annual changes in relative prices of the component vis-à-vis the headline.

${ }^{29}$ Grouping of shocks is the following: (i) External shocks - all the model shocks related to EMU and the US in the model (cost push shocks in the EMU and the US, demand shocks in the EMU and the US, interest rate shocks in the US, the cross exchange rate shock USD/EUR, world food and oil price shocks, and shocks to the natural rate of interest in the US). (ii) Cost push shocks - cost push shocks to core, food, and energy price inflation in Rwanda and shocks in Rwandan equilibrium relative price trends (iii) Non-agri demand shocks - demand shocks to nonagricultural output gap in Rwanda. (iv) Agri/harvest shocks - demand shocks to agricultural output gap in Rwanda. (v) UIP shocks - shocks to the nominal exchange rate. (vi) MP ER \& MP IR - monetary policy shocks including shocks to interest rates and shocks to the implicit exchange rate depreciation target, and (vii) Rest - all the other shocks in the model out of shocks listed in above groups.
} 
2019, tight monetary policy stance during 2017-2018 started to take a toll, preventing increase in core inflation.

Figure V.5: Decomposition of core inflation to structural shocks

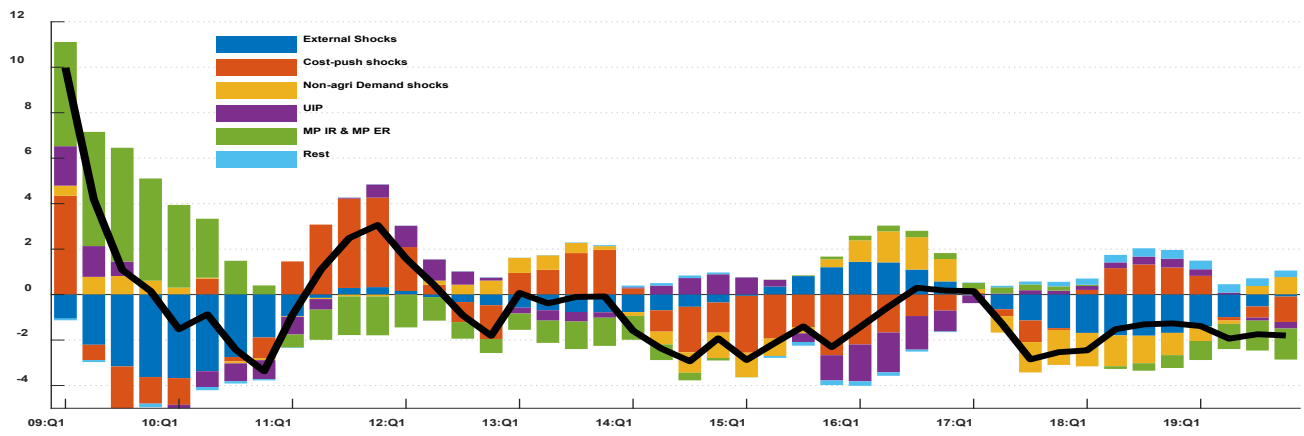

Source: Authors' computation

Note: Core price inflation rates plotted as deviations from their implicit targets.

Food price inflation in Rwanda was mostly shaped by the external factors, world food prices in particular, and supply shocks along with shocks to domestic agricultural production. Effects of domestic agricultural shocks are relatively mild while cost-push shocks shaped food price inflation heavily. The high share of supply shocks reflects the high volatility of food price inflation in Rwanda and also suggests that the agricultural output gap might capture only a part of supply effect local harvests have on food prices. World food prices declined significantly in 2009-2010 amid the global recession and contributed to slowing food price inflation in Rwanda although such effects were counteracted by domestic inflationary cost push shocks and monetary policy accommodation. World food prices had inflationary impact on domestic food prices during 20112013 and disinflationary effect in 2014-2015. The impact of domestic supply shocks along with domestic agricultural supply was limited at that time. Above average harvests and disinflationary supply brought food price inflation down despite moderate increase in world food prices. Reflecting below average harvest in the second half of 2019, food price inflation accelerated.

Figure V.6: Decomposition of food inflation to structural shocks

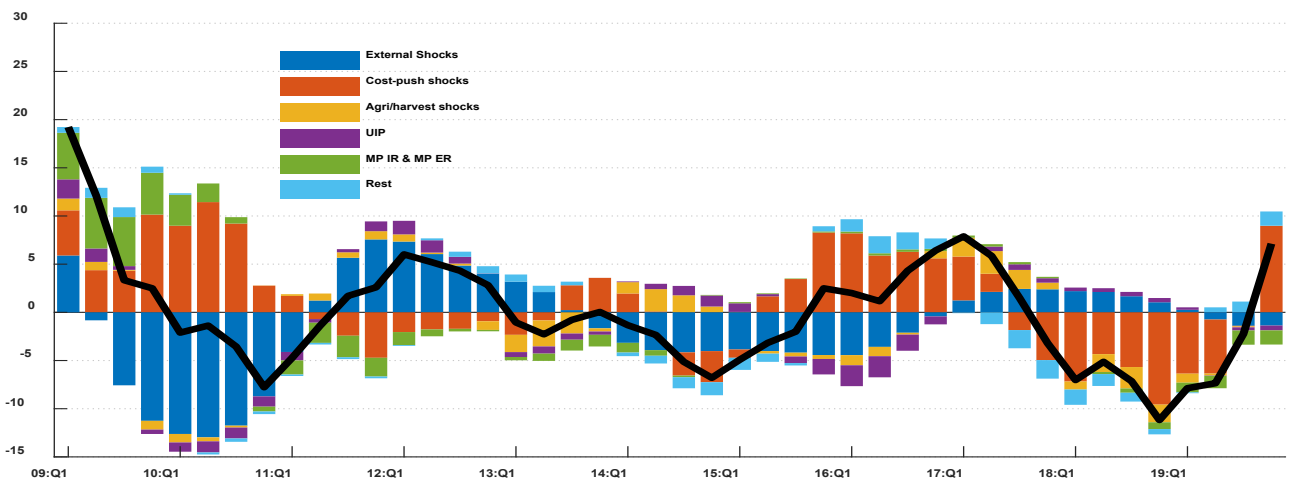

Source: Authors' computation

Note: Food price inflation rates plotted as deviations from their implicit targets. 


\section{Conclusion ANd The WAy AheAd}

Over the last few years some tangible progress has been achieved in developing modeling capacity at the BNR to support decision making in the modernized price-based policy framework. The contours and responsibilities of the forecasting team became clearer and the forecasting cycle process is better organized. The BNR staff acquired and continues to develop the core QPM and near-term forecasting and nowcasting modelling tools that inform medium-term macroeconomic projections. The model-based analysis and forecasting gained a more prominent role in staff policy presentations and policy discussions at the MPC meetings.

This work should continue to root and sustain the FPAS at the BNR. We identify several avenues which could potentially inform future FPAS-related research and development work at the BNR. A set of satellite models could be developed to support work of sectoral experts and cover, e.g. (i) agricultural sector, (ii) fiscal sector, (iii) banking sector and credit. Such models could be deployed to provide inputs to medium projections based on QPM, as in cases (i) and (ii), and to analyze sectoral implications of the medium-term macroeconomic projections as in case (iii). Obtaining projections for developments in the agricultural sector at least for the near-term appears to be particularly important. This sector remains relatively large in the Rwandan economy and agricultural output and supply of food products are very volatile and sensitive to weather conditions. In turn, swings in food supply have major implications for price dynamics. Conducting surveys of agricultural producers and evaluating a relationship between weather conditions and harvests to better gauge current and expected level of output are therefore important avenues for improving macroeconomic and policy projections. The external sector in the model could be further elaborated. The existing external sector can be (i) enriched by specifying relationships in a more structural form (as opposed to the reduced form AR processes) and (ii) the coverage in terms of number of countries and commodities can be expanded. Introducing structural relationships should be prioritized and would help formulating alternative macroeconomic scenarios of global developments because such relationships would deliver response of all foreign variables to structural shocks in the foreign sector. ${ }^{30}$ Extending the set of countries and commodities will likely require developing a joint satellite model for the external sector, which would establish the relationships among the regional trading partners and large global economies. Global VARs (GVAR) and IMF's Global Projection Model (GPM) are possible prototypes of such a model. ${ }^{31}$ Developing it could also be a project undertaken jointly by central banks from the

\footnotetext{
${ }^{30}$ Which is obviously not the case when foreign sector is described by a set of univariate AR processes and therefore with a shock to one of such processes affecting only one foreign variable.

${ }^{31}$ Chudik and Resaran (2014) and Pesaran and Schuermann (2004) discuss a GVAR.
} 
EAC, which would help share the costs of human resource and time investment. ${ }^{32}$ The UIP relationship could be further clarified and the country risk premium made a function of trade flows and terms-of-trade. This appears an interesting avenue because of dependence of Rwandan economy on exports of agricultural commodities such as tea and coffee, and on imports of fuels and energy. Hence, such a model extension would allow for linking outlooks for global commodities with the Rwandan trade balance and consequently for informing QPM projections of the country risk premium and the exchange rate.

It is important however that expanding modelling capacity and establishing FPAS are accompanied by further advances in the policy strategy and the policy implementation framework, and in external communications. It usually happens that countries transiting to price-based frameworks and some form of inflation targeting allow for greater flexibility and market determination of the exchange rate. As we have shown in this paper it should strengthen policy transmission and macroeconomic stabilization mechanism and focus monetary policy on the primary objective of achieving price stability. The conduct of open market operations and liquidity management could be usefully improved to ensure that the announced policy rate, the marginal rate in OMOs and the short-term interbank market rate are well aligned. That would eliminate conflicting policy signals, which take place when such rates differ substantially and systematically. Going forward, publishing macroeconomic projections and, in particular, conditional forecasts of the interest rate and exchange rate appears to be an important step in communicating BNR policy intentions to market participants. Together with a greater exchange rate flexibility, better alignment of the short-term money market rate and the key policy rate, external communications of projections should help strengthen the policy transmission from the policy rate to the longer-term market rates and support development of financial markets. For example, the forecast of the policy rate over the policy horizon-which is essentially the benchmark forward yield curve-would provide commercial banks with a critical input to better price longer-term financial products, which will in turn provide for better transmission of the current and expected policy rate to market rates for bonds, loans and deposits. The mutual dependence of advances in FPAS work, policy strategy, operations and communications yet again point to the importance of concerted efforts of the BNR in these areas, and should inform demand for further technical assistance, including from the IMF.

\footnotetext{
${ }^{32} \mathrm{We}$ also note that the complexity of the modelling apparatus and costs of maintenance will be permanently higher because the database and external forecasts will have to be collected for a much larger set of external variables.
} 


\section{REFERENCES}

Andrle, M., A. Berg, E. G. Berkes, R. A. Portillo, R.A. Morales, and J. Vlcek, 2013a, "Money Targeting in a Modern Forecasting and Policy Analysis System; an Application to Kenya," IMF Working Papers 13/239, International Monetary Fund.

Andrle, M., Berg, A., Morales, R.A., Portillo, R. and Vlcek, J., 2013b, "Forecasting and Monetary Policy Analysis in Low-Income Countries: Food and non-Food Inflation in Kenya", IMF Working Paper 13/61.

Berg, A., P. D. Karam, and D. Laxton, 2006a, "Practical Model-Based Monetary Policy Analysis; A How-To Guide," IMF Working Papers 06/81, International Monetary Fund.

Berg, A., P. D. Karam, and D. Laxton., 2006b, "A Practical Model-Based Approach to Monetary Policy Analysis - Overview," IMF Working Papers 06/80, International Monetary Fund.

Bergin, P. R., Glick, R., and Taylor, A. M., 2006. "Productivity, tradability, and the long-run price puzzle," Journal of Monetary Economics, Elsevier, vol. 53(8), pages 2041-2066, November.

Charry, L., Gupta, P. and V. Thakoor, 2014, "Introducing a Semi-Structural Macroeconomic Model for Rwanda," IMF Working Paper 14/159.

Czech National Bank "The Czech National Bank's Forecasting and Policy Analysis System".

Edited by W. Coats, D. Laxton, and D. Rose, Czech National Bank, 2003.

Chudik, A. and M. H. Pesaran, 2014, "Theory and Practice of GVAR Modeling," Journal of Economic Surveys, Vol. 30, Issue 1, pp. 165-197.

Egert, B. and J. Podpiera, 2008, "Structural Inflation and Real Exchange Rate Appreciation in visegrad-4 Countries: Balassa-Samuelson or Something Else?” CERP, Policy Insight \#20.

International Monetary Fund "Annual Report on Exchange Arrangements and Exchange Restrictions," 2018.

International Monetary Fund "Evolving Monetary Policy Frameworks in Low-Income and Other Developing Countries," Staff Report, 2015.

Karangwa, M., 2018, "The Role of Forecasting and Policy Analysis Systems (FPAS) Under the New Monetary Policy Framework," The Rwandan Banker, \# 31.

Musil, K., Pranovich, M., and J. Vlček, 2018, "Structural Quarterly Projection Model for Belarus," IMF Working Paper 18/254.

Pesaran, M. H., Schuermann, T., and S. M. Weiner, 2004, "Modeling Regional Interdependencies Using a Global Error-Correcting Macroeconometric Model," Journal of Business and Economic Statistics, Vol. 22, Issue 2, pp. 129-162.

Rusuhuzwa Kigabo, T. and P. R. Masson, 2012, "Design and Implementation of a Common Currency Area in the East African Community," University of Toronto, Working Paper 451.

Rwangombwa, J., 2018, "The Rationale for Adopting a Price Based Monetary Policy Framework at the National Bank of Rwanda," The Rwandan Banker, \# 31.

United Nations Economic Commission for Africa, "The East African Monetary Union: Ready or Not?" 2018. 


\section{REFERENCES}

Andrle, M., A. Berg, E. G. Berkes, R. A. Portillo, R.A. Morales, and J. Vlcek, 2013a, "Money Targeting in a Modern Forecasting and Policy Analysis System; an Application to Kenya," IMF Working Papers 13/239, International Monetary Fund.

Andrle, M., Berg, A., Morales, R.A., Portillo, R. and Vlcek, J., 2013b, "Forecasting and Monetary Policy Analysis in Low-Income Countries: Food and non-Food Inflation in Kenya", IMF Working Paper 13/61.

Berg, A., P. D. Karam, and D. Laxton, 2006a, "Practical Model-Based Monetary Policy Analysis; A How-To Guide," IMF Working Papers 06/81, International Monetary Fund.

Berg, A., P. D. Karam, and D. Laxton., 2006b, "A Practical Model-Based Approach to Monetary Policy Analysis - Overview," IMF Working Papers 06/80, International Monetary Fund.

Bergin, P. R., Glick, R., and Taylor, A. M., 2006. "Productivity, tradability, and the long-run price puzzle," Journal of Monetary Economics, Elsevier, vol. 53(8), pages 2041-2066, November.

Charry, L., Gupta, P. and V. Thakoor, 2014, "Introducing a Semi-Structural Macroeconomic Model for Rwanda," IMF Working Paper 14/159.

Czech National Bank "The Czech National Bank's Forecasting and Policy Analysis System".

Edited by W. Coats, D. Laxton, and D. Rose, Czech National Bank, 2003.

Chudik, A. and M. H. Pesaran, 2014, "Theory and Practice of GVAR Modeling," Journal of Economic Surveys, Vol. 30, Issue 1, pp. 165-197.

Egert, B. and J. Podpiera, 2008, "Structural Inflation and Real Exchange Rate Appreciation in visegrad-4 Countries: Balassa-Samuelson or Something Else?” CERP, Policy Insight \#20.

International Monetary Fund "Annual Report on Exchange Arrangements and Exchange Restrictions," 2018.

International Monetary Fund "Evolving Monetary Policy Frameworks in Low-Income and Other Developing Countries," Staff Report, 2015.

Karangwa, M., 2018, "The Role of Forecasting and Policy Analysis Systems (FPAS) Under the New Monetary Policy Framework," The Rwandan Banker, \# 31.

Musil, K., Pranovich, M., and J. Vlček, 2018, "Structural Quarterly Projection Model for Belarus," IMF Working Paper 18/254.

Pesaran, M. H., Schuermann, T., and S. M. Weiner, 2004, "Modeling Regional Interdependencies Using a Global Error-Correcting Macroeconometric Model," Journal of Business and Economic Statistics, Vol. 22, Issue 2, pp. 129-162.

Rusuhuzwa Kigabo, T. and P. R. Masson, 2012, "Design and Implementation of a Common Currency Area in the East African Community," University of Toronto, Working Paper 451.

Rwangombwa, J., 2018, "The Rationale for Adopting a Price Based Monetary Policy Framework at the National Bank of Rwanda," The Rwandan Banker, \# 31.

United Nations Economic Commission for Africa, "The East African Monetary Union: Ready or Not?" 2018. 


\section{APPENDIX A. Model Variables}

Variable

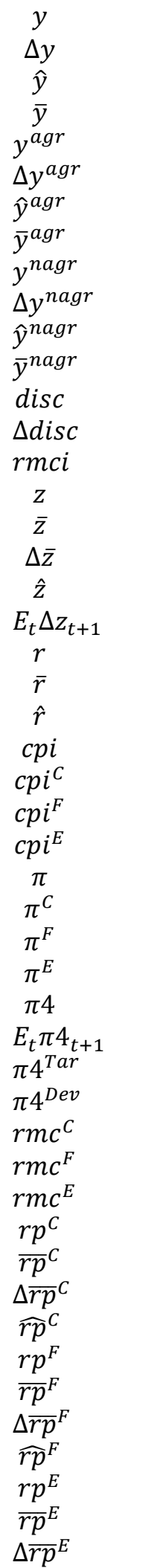

\section{Description}

Real GDP, $100 * \ln$

Real GDP growth, annualized q-o-q, percent

Output gap, percent

Potential GDP, $100 * \ln$

Real agricultural GDP, $100 * \ln$

Real agricultural GDP growth, annualized q-o-q, percent

Agricultural output gap, percent

Potential agricultural GDP, $100 * \ln$

Real non-agricultural GDP, $100 * \ln$

Real non-agricultural GDP growth, annualized q-o-q, percent

Non-agricultural output gap, percent

Potential non- agricultural GDP, $100 * \ln$

GDP discrepancy, $100 * \ln$

GDP discrepancy growth, annualized q-o-q, percent

Real monetary condition index, percent

Real exchange rate, $100 * \ln$

Equilibrium real exchange rate, $100 * \ln$

Equilibrium real exchange rate depreciation, annualized q-o-q, percent

Real effective exchange rate gap, percent

Expected equilibrium real exchange rate depreciation at $t$ for $t+1$, annualized q-o-q, percent

Real interest rate, percent

Equilibrium real interest rate, percent

Real interest rate gap, percent

Headline CPI, $100 * \ln$

Core CPI, $100 * \ln$

Food CPI, $100 * \ln$

Energy CPI, $100 * \ln$

Headline CPI inflation, annualized q-o-q, percent

Core CPI inflation, annualized q-o-q, percent

Food CPI inflation, annualized q-o-q, percent

Energy CPI inflation, annualized q-o-q, percent

Headline CPI inflation, y-o-y, percent

Expected headline CPI inflation in time $t$ for $t+1, \mathrm{y}-\mathrm{o}-\mathrm{y}$, percent

Inflation target for headline inflation, $y-0-y$, percent

Inflation deviation from the target, p.p.

Real marginal costs - core inflation, percent

Real marginal costs - food inflation, percent

Real marginal costs - energy inflation, percent

Relative price of core to headline, $100 * \ln$

Equilibrium relative price of core to headline, $100 * \ln$

Equilibrium relative price growth - core to headline, annualized q-o-q, percent

Relative price gap - core to headline, percent

Relative price of food to headline, $100 * \ln$

Equilibrium relative price of food to headline, $100 * \ln$

Equilibrium relative price growth - food to headline, annualized q-o-q, percent

Relative price gap - food to headline, percent

Relative price of energy to headline, $100 * \ln$

Equilibrium relative price of energy to headline, $100 * \ln$

Equilibrium relative price growth - energy to headline, annualized q-o-q, percent 


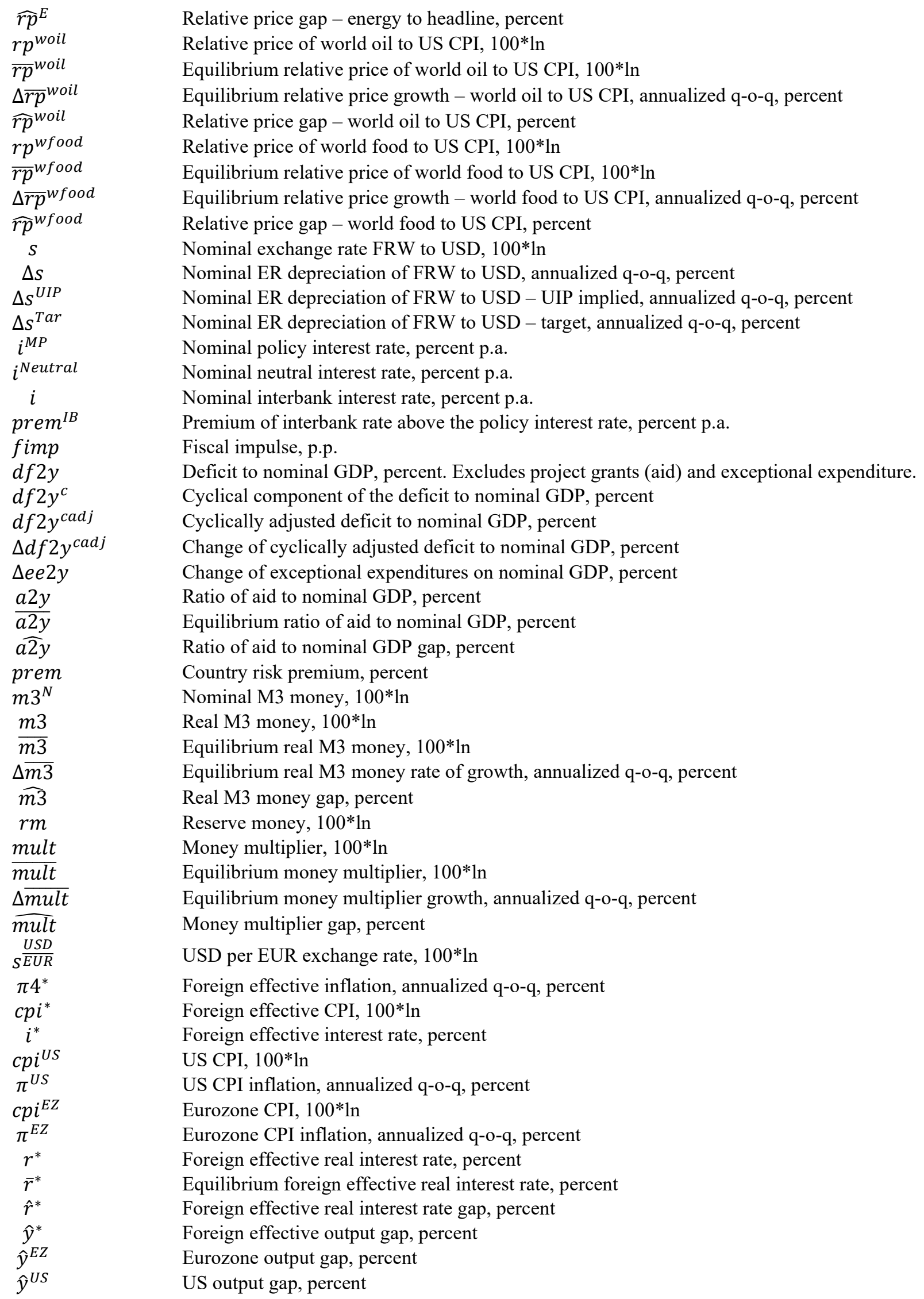


$\varepsilon^{\hat{y}^{a g r}}$

$\varepsilon^{\hat{y}^{n a g r}}$

$\varepsilon^{\Delta \bar{y}^{a g r}}$

$\varepsilon^{\Delta \bar{y}^{\text {nagr }}}$

$\varepsilon^{\pi C}$

$\varepsilon^{\pi F}$

$\varepsilon^{\pi E}$

$\epsilon_{t}^{c p i}$

$\varepsilon^{T T A R}$

$\varepsilon^{S}$

$\varepsilon^{\Delta s^{T A R}}$

$\varepsilon^{\Delta \bar{z}}$

$\varepsilon_{t}^{i^{M P}}$

$\epsilon_{t}^{\text {prem }^{I B}}$

$\varepsilon^{\hat{y}^{\text {country_code }}}$

$\varepsilon^{\pi^{\text {country_code }}}$

$\varepsilon_{t}^{i^{U S}}$

$\varepsilon^{\bar{r}^{u s}}$

$\varepsilon^{\Delta \overline{r p}}{ }^{C}$

$\varepsilon^{\Delta \overline{r p}}{ }^{E}$

$\varepsilon^{\Delta \overline{m 3}}$

$\varepsilon^{\widehat{m 3}}$

$\varepsilon^{\Delta v}$

$\varepsilon^{\Delta \overline{m u l t}}$

$\varepsilon^{\widehat{m u l t}}$

$\varepsilon^{\widehat{p p}^{\text {oil }}}$

$\varepsilon^{\Delta \overline{r p}}{ }^{\text {oil }}$

$\varepsilon^{\widehat{r p}^{\text {food }}}$

$\varepsilon^{\Delta \overline{r r p}^{\text {food }}}$

$\varepsilon^{\Delta s^{u s d e u r}}$

$\varepsilon_{t}^{d f 2 y^{c a d j}}$

$\varepsilon_{t}^{\overline{a 2 y}}$

$\varepsilon_{t} \overline{a 2 y}$

$\varepsilon_{t}^{a 2}$

excexp

$\epsilon_{t}^{\text {disc }}$

Shock to domestic agricultural output gap, percent

Shock to domestic non-agricultural output gap (aggregate demand shock), percent

Shock to the potential growth in agricultural sector, percent

Shock to the potential growth in non-agricultural sector, percent

Shock to core subcomponent of inflation, percent

Shock to food subcomponent of inflation, percent

Shock to energy subcomponent of inflation, percent

Measurement error in equation for headline CPI as a weighted average of CPI subcomponents, percent

Shock to inflation target, percent

Shock to the nominal effective exchange rate, percent

Shock to the nominal effective exchange rate target, percent

Shock to the long-term rate of change in real effective exchange rate, percent

Shock to the domestic policy interest rate (monetary policy shock), percent

Shock to the premium of the overnight interbank money market rate over the policy rate, percent

Shock to foreign (country_code $=\mathrm{EZ}$ or US) output gap, percent

Shock to foreign (country_code $=\mathrm{EZ}$, or US) inflation, percent

Shock to the US interest rate, percent

Shock to the US equilibrium real interest rate, percent

Shock to the rate of growth of trend in domestic core CPI subcomponent relative to headline CPI, percent

Shock to the rate of growth of trend in domestic energy CPI subcomponent relative to headline CPI, percent

Shock to the trend of real money balances, percent

Shock to the gap of real money balances, percent

Shock to the velocity of money, percent

Shock to the trend of real money balances, percent

Shock to the gap of real money balances, percent

Shock to the cyclical component (gap) in relative oil prices, percent

Shock to the trend in relative oil prices, percent

Shock to the cyclical component (gap) in world food prices relative to US CPI, percent

Shock to the trend in world food prices relative to US CPI, percent

Shock to the USDEUR nominal exchange rate, percent

Shock to the ratio of cyclically-adjusted deficit to GDP, percent

Shock to the gap of the ratio of aid to GDP, percent

Shock to the trend of the ratio of aid to GDP, percent

Shock to the ratio of exceptional expenditures to GDP, percent

Measurement error due to varying weights of agricultural and non-agricultural production in total output, percent 


\section{APPENDIX B. Model Equations}

Only dynamic equations and definitions for trends and gaps are reported. Remaining are definitions for growth rates. All variables are in natural logs of respective variables unless noted otherwise. $\Delta$ is for q-o-q annualized growth rates, and $\Delta 4$ is for y-o-y growth rates.

Real GDP

\section{Real GDP - Agriculture Block}

$$
\begin{gathered}
\Delta y_{t}=w^{a g r} \Delta y_{t}^{a g r}+\left(1-w^{a g r}\right) \Delta y_{t}^{\text {nagr }}+\Delta d i s c_{t} \\
\operatorname{disc} c_{t}=\operatorname{dis} c_{t-1}+\epsilon_{t}^{\text {disc }} \\
\hat{y}_{t}=w^{a g r} \hat{y}_{t}^{a g r}+\left(1-w^{a g r}\right) \hat{y}_{t}^{\text {nagr }} \\
y_{t}=\hat{y}_{t}+\bar{y}_{t}
\end{gathered}
$$

$$
\begin{gathered}
y_{t}^{a g r}=\hat{y}_{t}^{a g r}+\bar{y}_{t}^{a g r} \\
\hat{y}_{t}^{a g r}=b_{11} \hat{y}_{t-1}^{a g r}+\epsilon_{t}^{a g r} \\
\Delta \bar{y}_{t}^{a g r}=\rho^{\Delta \bar{y}^{a g r}} \Delta \bar{y}_{t-1}^{a g r}+\left(1-\rho^{\Delta \bar{y}^{a g r}}\right) \Delta \bar{y}_{s s}^{a g r}+\epsilon_{t}^{\Delta \bar{y}^{a g r}}
\end{gathered}
$$

Real GDP - Non-agriculture Block

$$
\begin{gathered}
y_{t}^{\text {nagr }}=\hat{y}_{t}^{\text {nagr }}+\bar{y}_{t}^{\text {nagr }} \\
\hat{y}_{t}^{\text {nagr }}=b_{12} \hat{y}_{t-1}^{\text {nagr }}-b_{22} r m c i_{t}+b_{32} \hat{y}_{t}^{*}+b_{42} f i m p_{t}+b_{52}\left(\widehat{a 2 y_{t}}-\widehat{a 2 y_{t-1}}\right) \\
+\varepsilon_{t}^{\hat{y}^{n a g r}}
\end{gathered}
$$

Real monetary conditions index

Inflation

$$
r m c i_{t}=-b_{14} \hat{z}_{t}+\left(1-b_{14}\right) \hat{r}_{t}
$$

Inflation - Core inflation

$$
c p i_{t}=w^{C} c p i_{t}^{C}+w^{F} c p i_{t}^{F}+\left(1-w^{C}-w^{F}\right) c p i_{t}^{E}+\epsilon_{t}^{c p i}
$$

$$
\begin{gathered}
\pi_{t}^{C}=a_{11} E_{t} \pi_{t+1}^{C}+\left(1-a_{11}\right) \pi_{t-1}^{C}+a_{21} r m c_{t}^{C}+\varepsilon_{t}^{\pi^{C}} \\
r m c_{t}^{C}=a_{31} \hat{y}_{t}^{\text {nagr }}+\left(1-a_{31}\right)\left(\hat{z}_{t}-\widehat{r p}_{t}^{C}\right)
\end{gathered}
$$

Inflation - Food price inflation

$$
\begin{gathered}
\pi_{t}^{F}=a_{12} E_{t} \pi_{t+1}^{F}+\left(1-a_{12}\right) \pi_{t-1}^{F}+a_{22} r m c_{t}^{F}+\varepsilon_{t}^{\pi^{F}} \\
r m c_{t}^{F}=a_{32} \hat{y}_{t}^{\text {nagr }}-a_{42} \hat{y}_{t}^{\text {agr }}+\left(1-a_{32}\right)\left(\widehat{r p}_{t}^{\text {ffood }}+\hat{z}_{t}-\widehat{r p}_{t}^{F}\right)
\end{gathered}
$$

Inflation - Energy price inflation

$$
\begin{gathered}
\pi_{t}^{E}=a_{13} E_{t} \pi_{t+1}^{E}+\left(1-a_{13}\right) \pi_{t-1}^{E}+a_{23} r m c_{t}^{E}+\varepsilon_{t}^{\pi^{E}} \\
r m c_{t}^{E}=a_{33} \hat{y}_{t}^{\text {nagr }}+\left(1-a_{33}\right)\left(\widehat{r p}_{t}^{\text {woil }}+\hat{z}_{t}-\widehat{r p}_{t}^{E}\right)
\end{gathered}
$$

Monetary policy - exchange rate

$$
\Delta s_{t}=w^{U I P} \Delta s_{t}^{U I P}+\left(1-w^{U I P}\right) \Delta s_{t}^{T a r}
$$




$$
\begin{gathered}
\Delta s_{t}^{T a r}=\left(\Delta \bar{z}_{t}+\pi 4_{t}^{T a r}-\pi 4_{t}^{*}\right)-f_{12} E_{t} \pi 4_{t+1}^{D e v}-f_{22} \hat{z}_{t}+\varepsilon_{t}^{\Delta s^{T a r}} \\
s_{t}=e_{1}\left(s_{t-1}+\frac{2}{4}\left(\Delta \bar{z}_{t}+\pi_{t}-\bar{\pi}^{*}\right)\right)+ \\
\ldots+\left(1-e_{1}\right) E_{t} s_{t+1}-\left(\frac{i_{t}}{4}-\frac{i_{t}^{*}}{4}-\frac{\text { prem }_{t}}{4}\right)+\varepsilon_{t}^{s}
\end{gathered}
$$

Monetary policy - interest rates

$$
\begin{gathered}
i_{t}^{M P}=g_{1} i_{t-1}^{M P}+\left(1-g_{1}\right)\left(i_{t}^{\text {Neutral }}+g_{2}\left(E_{t} \pi 4_{t+1}^{\text {Dev }}\right)+g_{3} \hat{y}_{t}^{\text {nagr }}\right)+\varepsilon_{t}^{i^{M P}} \\
\pi 4_{t+1}^{\text {Dev }}=E_{t} \pi 4_{t+1}-\pi 4_{t+1}^{\text {Tar }} \\
i_{t}^{\text {Neutral }}=\bar{r}_{t}+E_{t} \pi_{t+1}-\text { prem }_{t}^{I B}
\end{gathered}
$$

Market interest rates

$$
\begin{gathered}
i_{t}=i_{t}^{M P}+\text { prem }_{t}^{I B} \\
\text { prem }_{t}^{I B}=\rho^{\text {prem }^{I B}} \text { prem }_{t-1}^{I B}+\left(1-\rho^{\text {prem }^{I B}}\right) \text { prem }_{s S}^{I B}+\varepsilon_{t}^{\text {prem }^{I B}}
\end{gathered}
$$

Fiscal block

$$
\begin{gathered}
\operatorname{fimp}_{t}=\Delta \mathrm{df} 2 \mathrm{y}_{\mathrm{t}}^{\text {cadj }}+\Delta e e 2 y_{t} \\
d f 2 y_{t}=d f 2 y_{t}^{c}+d f 2 y_{t}^{c a d j} \\
d f 2 y_{t}^{c}=d_{1} \hat{y}_{t}^{\text {nagr }} \\
d f 2 y_{t}^{c a d j}=\rho^{d f 2 y^{c a d j}} d f 2 y_{t-1}^{c a d j}+\left(1-\rho^{d f 2 y^{c a d j}}\right) d f 2 y_{s s}^{c a d j}+\varepsilon_{t}^{d f 2 y^{c a d j}}
\end{gathered}
$$

Aid block

$$
\begin{gathered}
a 2 y_{t}=\overline{a 2 y}_{t}+\widehat{a 2 y}{ }_{t} \\
\overline{a 2 y}_{t}=\rho^{\overline{a 2 y}} \overline{a 2 y}_{t-1}+\left(1-\rho^{\overline{a 2 y}}\right) \overline{a 2 y}_{s s}+\varepsilon_{t}^{\overline{a 2 y}} \\
\widehat{a 2 y_{t}}=\rho^{\widehat{a 2 y}} \widehat{a 2 y}_{t-1}+\varepsilon_{t}^{\widehat{a 2 y}}
\end{gathered}
$$

\section{Real interest rate}

$$
\begin{gathered}
r_{t}=i_{t}-E_{t} \pi 4_{t+1} \\
r_{t}=\bar{r}_{t}+\hat{r}_{t} \\
\bar{r}_{t}=\rho^{\bar{r}} \bar{r}_{t-1}+\left(1-\rho^{\bar{r}}\right) \bar{r}_{s s}+\varepsilon_{t}^{\bar{r}}
\end{gathered}
$$

Real exchange rate

$$
\begin{gathered}
z_{t}=s_{t}+c p i_{t}^{*}-c p i_{t} \\
z_{t}=\bar{z}_{t}+\hat{z}_{t} \\
\Delta \bar{z}_{t}=\rho^{\Delta \bar{z}} \Delta \bar{z}_{t-1}+\left(1-\rho^{\Delta \bar{z}}\right) \Delta \bar{z}_{s s}+\varepsilon_{t}^{\Delta \bar{z}}
\end{gathered}
$$

\section{Equilibrium version of UIP}

$$
\begin{gathered}
\operatorname{prem}_{t}=\bar{r}_{t}-\bar{r}_{t}^{*}-E_{t} \Delta \bar{z}_{t+1} \\
\text { Relative prices } \\
r p_{t}^{C}=c p i_{t}^{C}-c p i_{t} \\
r p_{t}^{C}=\overline{r p}_{t}^{C}+\widehat{r p}_{t}^{C} \\
\Delta \overline{r p}_{t}^{C}=\rho^{\overline{r p}} \Delta \overline{r p}_{t-1}^{C}+\left(1-\rho^{\overline{r p}}\right) \Delta \overline{r p}_{s s}^{C}+\varepsilon_{t}^{\Delta \overline{r p}} C \\
r p_{t}^{F}=c p i_{t}^{F}-c p i_{t}
\end{gathered}
$$




$$
\begin{gathered}
r p_{t}^{F}=\overline{r p}_{t}^{F}+\widehat{r p}_{t}^{F} \\
\Delta \overline{r p}_{t}^{F}=\rho^{\overline{r p}^{F}} \Delta \overline{r p_{t-1}^{F}}+\left(1-\rho^{\overline{r p}^{F}}\right) \Delta \overline{r p}_{s s}^{F}+\varepsilon_{t}^{\Delta \overline{r p}}{ }^{F} \\
r p_{t}^{E}=c p i_{t}^{E}-c p i_{t} \\
r p_{t}^{E}=\overline{r p}_{t}^{E}+\widehat{r p}_{t}^{E} \\
{ }^{C} \overline{r p}_{t}^{C}+w^{F} \overline{r p}_{t}^{F}+\left(1-w^{C}-w^{F}\right) \overline{r p}_{t}^{E}=0
\end{gathered}
$$

Money demand block

$$
\begin{aligned}
& m 3_{t}^{N}=m 3_{t}+c p i_{t} \\
& m 3_{t}=\overline{m 3}_{t}+\widehat{m 3}_{t} \\
& \widehat{m 3}_{t}=c_{1} \widehat{m 3}_{t-1}+\left(1-c_{1}\right)\left(c_{2} \hat{y}_{t}^{n a g r}-c_{3} \hat{r}_{t}\right)+\varepsilon_{t}^{\widehat{m 3}} \\
& \Delta \overline{m 3}_{t}=\rho^{\overline{m 3}} \Delta \overline{m 3}_{t-1}+\left(1-\rho^{\overline{m 3}}\right)\left(\Delta \bar{y}_{t}-\Delta v_{t}-c_{4}\left(\bar{r}_{t}-\bar{r}_{t-1}\right)\right)+\varepsilon_{t}^{\Delta \overline{m 3}} \text {, } \\
& \Delta v_{t}=\rho^{\Delta v} \Delta v_{t-1}+\left(1-\rho^{\Delta v}\right) \Delta v_{s S}+\varepsilon_{t}^{\Delta v} \\
& r m_{t}=m 3_{t}+\text { mult }_{t} \\
& \text { mult }_{t}=\overline{\text { mult }}_{t}+\widehat{\text { mult }}_{t} \\
& \Delta \overline{m u l t}_{t}=\rho^{\overline{m u l t}} \Delta m u l t_{t-1}+\left(1-\rho^{\overline{m u l t}}\right) \Delta \overline{m u l t}_{s S}+\varepsilon_{t}^{\Delta \overline{m u l t}} \\
& \widehat{\text { mult }}_{t}=\rho^{\widehat{\text { mult }}} \widehat{\text { mult }}_{t-1}+\varepsilon_{t} \widehat{\text { mult }}
\end{aligned}
$$

World oil price

$$
\begin{gathered}
r p_{t}^{\text {woil }}=p_{t}^{\text {woil }}-p_{t}^{U S} \\
\widehat{r p}_{t}^{\text {woil }}=r p_{t}^{\text {woil }}-\overline{r p}_{t}^{\text {woil }} \\
\widehat{r p}_{t}^{\text {woil }}=\rho^{\widehat{r p}^{\text {woil }}} \cdot \widehat{r p}_{t-1}^{\text {woil }}+\varepsilon_{t}^{\widehat{r p}^{\text {woil }}} \\
\Delta \overline{r p}_{t}^{\text {woil }}=\rho^{\Delta \overline{r p}^{\text {woil }}} \Delta \overline{r p}_{t-1}^{\text {woil }}+\left(1-\rho^{\Delta \overline{r p}{ }^{\text {woil }}}\right) \Delta \overline{r p}_{s S}^{\text {woil }}+\varepsilon_{t}^{\Delta \overline{r p}}{ }^{\text {woil }}
\end{gathered}
$$

\section{World food price}

$$
\begin{gathered}
r p_{t}^{w f o o d}=p_{t}^{w f o o d}-p_{t}^{U S} \\
\widehat{r p}_{t}^{w \text { food }}=r p_{t}^{w \text { food }}-\overline{r p}_{t}^{w \text { food }} \\
\widehat{r p}_{t}^{w \text { food }}=\rho^{\widehat{r p}^{w f o o d}} \cdot \widehat{r p}_{t-1}^{w f o o d}+\varepsilon_{t}^{\widehat{r p}^{w f o o d}} \\
\Delta \overline{r p}_{t}^{w \text { food }}=\rho^{\Delta \overline{r p}^{w f o o d}} \Delta \overline{r p}_{t-1}^{w f o o d}+\left(1-\rho^{\Delta \overline{r p}^{w f o o d}}\right) \Delta \overline{r p}_{s s}^{w f o o d}+\varepsilon_{t}^{\Delta \overline{r p}^{w f o o d}}
\end{gathered}
$$

\section{External sector}

$$
\begin{gathered}
\pi_{t}^{*}=w^{U S} \pi_{t}^{U S}+\left(1-w^{U S}\right)\left[\pi_{t}^{E M U}+s_{t}^{\frac{U S D}{E U R}}\right] \\
\hat{y}^{*}=w^{U S} \hat{y}_{t}^{U S}+\left(1-w^{U S}\right) \hat{y}_{t}^{E M U} \\
r_{t}^{*}=i_{t}^{U S}-E_{t} \pi_{t+1}^{U S} \\
r_{t}^{*}=\bar{r}_{t}^{*}+\hat{r}_{t}^{*} \\
\bar{r}_{t}^{*}=\rho^{\bar{r}^{*}} \bar{r}_{t-1}^{*}+\left(1-\rho^{\bar{r}^{*}}\right) \bar{r}_{s S}^{*}+\varepsilon_{t}^{\bar{r}^{*}}
\end{gathered}
$$


APPENDIX C. Calibration of the Model Coefficients

\begin{tabular}{|c|c|c|c|}
\hline Coefficient & Value & Coefficient & Value \\
\hline \multicolumn{2}{|c|}{ Real GDP-Agriculture Block } & \multicolumn{2}{|c|}{ Fiscal block } \\
\hline$w^{a g r}$ & 0.3 & $d_{1}$ & 0.4 \\
\hline \multicolumn{2}{|c|}{ Real GDP-Agriculture Block } & $\rho^{d f 2 y^{\text {cadj }}}$ & 0.75 \\
\hline$b_{11}$ & 0.4 & $d f 2 y_{s s}^{c a d j}$ & 4 \\
\hline$\rho^{\Delta \bar{y}^{a g r}}$ & 0.8 & \multicolumn{2}{|c|}{ Aid block } \\
\hline$\Delta \bar{y}_{s s}^{a g r}$ & 8.158 & $\rho^{\overline{a 2 y}}$ & 0.75 \\
\hline \multicolumn{2}{|c|}{ Real GDP - Non-agriculture Block } & $\overline{\overline{a 2 y}}_{s s}$ & 3 \\
\hline$b_{12}$ & 0.75 & $\rho^{\frac{a j}{a 2 y}}$ & 0.5 \\
\hline$b_{22}$ & 0.1 & \multicolumn{2}{|c|}{ Real interest rate } \\
\hline$b_{32}$ & 0.3 & $\rho^{\bar{r}}$ & 0.8 \\
\hline$b_{42}$ & 0.1 & $\bar{r}_{S S}$ & 2 \\
\hline$b_{52}$ & 0.1 & \multicolumn{2}{|c|}{ Real exchange rate } \\
\hline$\rho^{\Delta \bar{y}^{n a g r}}$ & 0.8 & $\rho^{\Delta \bar{z}}$ & 0.85 \\
\hline$b_{13}$ & 0.035 & $\Delta \bar{z}_{S S}$ & 0 \\
\hline$b_{14}$ & 0.5 & \multicolumn{2}{|c|}{ Relative prices } \\
\hline & & $\rho^{\overline{r p} \bar{p}^{C}}$ & 0.8 \\
\hline$w^{c}$ & 0.59 & $\Delta \overline{r p}_{s s}^{C}$ & -1 \\
\hline$w^{F}$ & 0.34 & $\rho^{\overline{r p p^{F}}}$ & 0.8 \\
\hline \multicolumn{2}{|c|}{ Inflation-Core inflation } & $\Delta \overline{r p}_{s S}^{F}$ & 1 \\
\hline$a_{11}$ & 0.5 & \multicolumn{2}{|c|}{ Money demand block } \\
\hline$a_{21}$ & 0.2 & $c_{1}$ & 0.5 \\
\hline$a_{31}$ & 0.7 & $c_{2}$ & 1.5 \\
\hline \multicolumn{2}{|c|}{ Inflation - Food price inflation } & $c_{3}$ & 0.5 \\
\hline$a_{12}$ & 0.5 & $c_{4}$ & 0.5 \\
\hline$a_{22}$ & 0.3 & $\rho^{\frac{1}{m 3}}$ & 0.8 \\
\hline$a_{32}$ & 0.7 & $\rho^{\Delta v}$ & 0.95 \\
\hline$a_{42}$ & 1.6 & $\Delta v_{s S}$ & -8 \\
\hline \multicolumn{2}{|c|}{ Inflation - Energy price inflation } & $\rho^{\frac{s}{m u l t}}$ & 0.9 \\
\hline$a_{13}$ & 0.2 & $\Delta \overline{\overline{m u l t}}_{s s}$ & 3 \\
\hline$a_{23}$ & 0.3 & $\rho^{\overline{\text { mult }}}$ & 0.5 \\
\hline$a_{33}$ & 0.7 & \multicolumn{2}{|c|}{ World oil price } \\
\hline \multicolumn{2}{|c|}{ Monetary policy - exchange rate } & $\rho^{\widehat{r p}} \widehat{p}^{\text {woil }}$ & 0.75 \\
\hline$w^{U I P}$ & 0.5 & $\rho^{\Delta \overline{r p} \text { woil }}$ & 0.9 \\
\hline$f_{12}$ & 0.3 & $\Delta \bar{r} \overline{s S}_{s \text { wil }}^{\text {woil }}$ & 0 \\
\hline$f_{22}$ & 0.85 & \multicolumn{2}{|c|}{ World food price } \\
\hline$e_{1}$ & 0.8 & $\rho^{\widehat{r p p}^{w f o o d}}$ & 0.75 \\
\hline \multicolumn{2}{|c|}{ Monetary policy - interest rates } & $\rho^{\Delta \overline{r p} \text { woil }}$ & 0.9 \\
\hline$g_{1}$ & 0.8 & $\Delta \overline{r p} \overline{s S}_{s \text { food }}^{\text {for }}$ & 0 \\
\hline$g_{2}$ & 0.25 & \multicolumn{2}{|c|}{ External sector } \\
\hline$g_{3}$ & 0.2 & $w^{U S}$ & 0.6 \\
\hline$w^{T B}$ & 0 & $\rho^{\bar{r}^{*}}$ & 0.9 \\
\hline \multicolumn{2}{|c|}{ Market interest rates } & $\bar{r}_{S S}^{*}$ & 1 \\
\hline$\rho^{\text {prem }}$ & 0.6 & & \\
\hline $\operatorname{prem}_{s S}^{T B}$ & 1.5 & & \\
\hline$\rho^{\text {prem }^{I B}}$ & 0.6 & & \\
\hline prem $_{s s}^{I B}$ & 1.5 & & \\
\hline
\end{tabular}

